\title{
Data-Driven Analytics for China's Overseas Construction Projects in the Contexts of the Maritime Silk Road and Global Maritime Network
}

\author{
Zhi-Hua Hu ii \\ Logistics Research Center, Shanghai Maritime University, Shanghai 201306, China \\ Correspondence should be addressed to Zhi-Hua Hu; zhhu@shmtu.edu.cn
}

Received 17 May 2020; Revised 11 October 2020; Accepted 11 November 2020; Published 27 November 2020

Academic Editor: Guangdong Wu

Copyright ( 2020 Zhi-Hua Hu. This is an open access article distributed under the Creative Commons Attribution License, which permits unrestricted use, distribution, and reproduction in any medium, provided the original work is properly cited.

\begin{abstract}
The Belt and Road (BR) Initiative (BRI) is usually examined in geopolitics perspectives, while the studies ignored the consistency of the BRI with the world economy and China's historical international business. This study developed a maritime big data system to analyze global interactions upon the global maritime network generated from the system. The BR is coupled with Chinese overseas construction projects (COCPs) in the context of the global maritime network by data-driven analytics methods. A network is developed by extracting the spatial interactions among maritime ports, and time and spatial analyzing methods are used for vessel flows among maritime ports. Then, nine analytical experiments are conducted to examine the relations between COCP and BRI. The figure of the BR emerges from COCP and the maritime network. The BR region and especially the $21 s t$ Century Maritime Silk Road (MSR) had emerged as a definite shape ten years ago. The BRI creates additional opportunities in developing the Silk Road Economic Belt (SREB) and the connectivity between BR and the world. The policy implications considering China, regions, and global communities are further be studied. The BR is investigated by using the big data coupled with the COCP other than just depicting from geographical and economic views.
\end{abstract}

\section{Introduction}

Launched by China in 2013, the Belt and Road (BR) Initiative (BRI) [1] aims to establish new land and maritime trading routes, links, and business opportunities by further connecting China, Asia, Europe, Africa, and countries with various independent economies (IEs) along with the land and maritime corridors. In BRI, the interconnection is embodied by interconnected infrastructures among the IEs in the BR. More infrastructure engineering contracts, especially on transport and logistics facilities and corridors, will be generated and propelled by China and the IEs in BR. Unlike many BRI studies focusing on its geopolitics ambitions and impacts [2], this study looks into the relations among BRI, China's overseas construction projects (COCPs) and maritime networks.

The COCP contracts are booming due to the engagement of China's "go out" strategy and national economy development [3]. In another aspect, the trade cargos among the IEs are usually transported by maritime vessels, even accounting about $90 \%$ of the total trade volume. Trade and investment are ways for an IE to cooperate and make profits with other IEs. This study examined the relations between the maritime transport system and the COCP partially because big construction projects involve the transportation of vast amounts of resources.

This study was activated by the following insights from the related literature on China's oversea engineering projects and the BRI. First, these oversea projects sometimes are explained as political purposes other than economy and trade targets. However, China's companies scatter these projects in many countries in recent years. At least, it is beneficial to examine the possible connections between these projects and the economic issues. Second, the BRI is generally taken as a geopolitical of China and a strategy of product exports. However, an economical and trading 
strategy cannot be sustainable in the long run if it is just political. In this study, activated by these observations from literature and questions, data-driven analysis is conducted to visualize and verify the relationship among China's oversea engineering projects, BRI, and the economy and trading situations and tendencies. Here, due to the complexities among them and the complexities of economy and trading issues, this study used data-driven maritime networks to represent the aspects of economy and trading. Besides, when their relations can be quantized, prediction methods can be developed to find investment opportunities for engineering projects and maritime trading.

These curiosities (on the relations among the China's oversea engineering projects, BRI, and maritime networks) initialized a visualization map based on a big data system [4]. Here, three data sets are presented in Figure 1: the COCP in 2015-2017 [5], the IEs in the world, and 65 IEs in BR. The IEs in BR are painted by green color first; the landlocked IEs and maritime IEs with construction contracts with China are then marked by brown and blue colors individually. Here, 93 IEs are involved in the 1296 COCP projects in the thirteen years; 35 of the 65 BR IEs raised construction contracts with China. Intuitively, China gained contracts from most seaborne IEs except for countries in west Europe and some landlocked IEs. This visualization confirms that there are strong relations among COCP, maritime network, and BR.

To examine the relations among $\mathrm{COCP}$, maritime network, and BRI, this study created a maritime network from a port and shipping big data system [4]; the COCP and BR IEs are then attached to the IEs in the maritime network to build an embodied maritime network. Comparing with the pioneering studies on COCP, maritime, and BRI studies, this paper contributes to the literature in the following aspects. First, the COCP is examined to reveal the time and spatial distribution patterns, while existing studies focused on specific contracts or regions. Second, the COCP is embedded in the global maritime network that is the carrier of bulk resources and products. To the best of our knowledge, it is the first time to examine COCP or general overseas construction contracts in the context of the global maritime network. Third, spatial relations are analyzed between COCP and BRI by geographical visualization.

The rest of the paper is organized as follows: First, the studies related to COCP, maritime network, and BRI are reviewed. Then, a research framework is introduced, as well as the data-driven and network-based research methods. Then, the two main data sets (COCP and the maritime network) are elucidated in detail. A series of experiments are conducted to answer the questions proposed above. Finally, the results are discussed, and the study is concluded.

\section{Related Studies}

2.1. China's Overseas Construction. A temporal history of China's oversea engineering contracting is given first in the following. In the past seventy years, from 1950 to 1978 , China's oversea engineering contracting mainly focused on developing foreign aid business to friendly countries. Under the planned economy system, the government led and used administrative means to arrange construction tasks. With the reform and opening in the late 1970s, a few companies participate in international market competition. The primary contracting model for national government loan projects and various private investment projects is the traditional design-tender-construction contracting model. In the late 1980s, China' companies began to develop the design-build (DB) model, design-construction-procurement general contracting (EPC), turnkey model (Turnkey), etc. In the 21st century, the EPC model has gradually become the mainstream contracting model in oversea engineering projects. With the comprehensive advantages of engineering services formed by different types of enterprises in China, more companies provide planning, survey, design, construction, and construction services for oversea engineering projects. The companies also gradually adopt new models such as PM (project-management) and PMC (projectmanagement-contracting) in practices. In recent years, more financial support methods and business models have emerged to support COCP, such as BOT (build-operatetransfer), PPP (public-private partnership), and PFI (private financing activities). These new models help the companies to achieve the integration of government and private capital in infrastructure construction. China devoted about fifty years to anticipate the oversea engineering projects and gradually becomes a primary contributor in oversea engineering contracting.

Considering the scales of China's oversea engineering companies and countries with contracting projects, the development of COCP can be divided into four stages. First, from the early 1950 s to the late 1970 s, China provided a large amount of economic and technical assistance to developing countries in Asia, Africa, and Latin America, many of which were not in the traditional form of project contracting. Second, during the 1980s, the scale of the industry began to appear and the ability of Chinese contractors to develop international markets has been dramatically improved. However, in the global top 250/225 international engineering contractors by the "Engineering News Record" (ENR) (the data in this section are compiled from https:// www.enr.com/), in 1990, only three Chinese companies were shortlisted. Third, from 1990 to 2005, China's international engineering contracting industry entered a stage of rapid growth, with continuous improvement incorporate strength and significant growth in turnover and contract value. At this stage, the number of Chinese companies selected as ENR Global 250/225 International Engineering Contractors made a breakthrough, reaching 46 in 2005, only less than the United States. Fourth, since 2005, under economic globalization, China's international engineering contracting industry has maintained steady development. The number of foreign contracted engineering companies increased from 1,609 in 2005 to nearly 4,500 in 2017, and the overall strength and competitiveness have been greatly enhanced. In 2017, 65 mainland Chinese companies were on the ENR list, ranking first in the world. In 2020, this number reaches 74 .

The COCP contractors have become more active in recent years due to the encouragement and support by the Chinese government, coupled with the pressure of intensive 


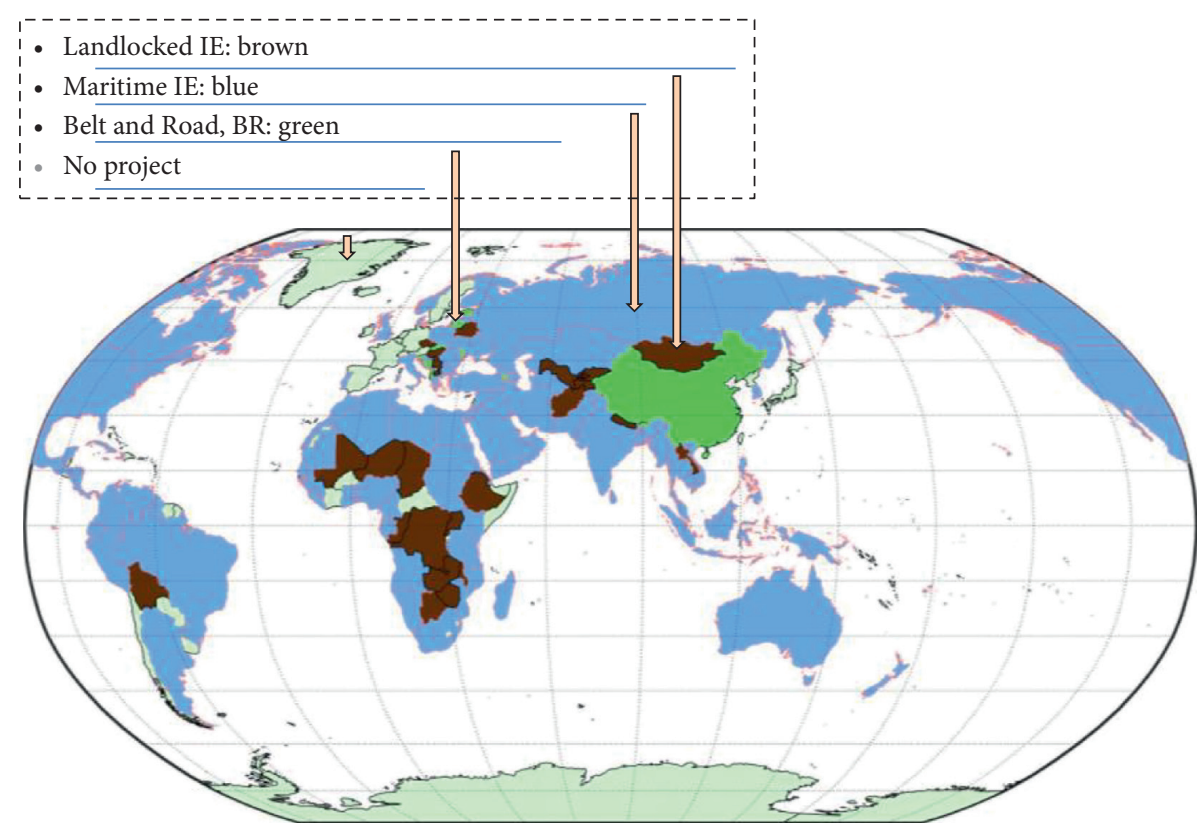

Figure 1: Spatial distribution of China's overseas construction projects (2005-2017).

competition within the domestic market [6]. The COCP contractors have made significant progress in international construction markets. China's history of lifting Chinese out of poverty over the last forty years is a lesson for many developing and undeveloped countries [7]. The COCP will result in both the projects themselves and the sustainable development of the host countries [7]. Although the COCP contractors play a significant role in the global construction market [8], the traditional multinational enterprise theories may not explain its complexity [8]. The COCP practices are featured by governmental regulations, professional qualification systems, procurement systems, labor relations, and social and environmental responsibility [9]. The COCP contractors generally commit substantial resources [10]. However, as criticized, newly emerged Chinese businesses threaten local entrepreneurs who lack the resources necessary to parry Chinese competition. The COCP projects even produce a growing rate of national unemployment [11]. The challenges faced by COCP companies include environmental and political problems [12]. Social and environmental costs should be considered by COCP [13].

The COCP continues to grow while facing opportunities and threats simultaneously [10]. The COCP companies working mostly in unstable nations face potential risks. The COCP may be terminated or suspended for various reasons in the host countries [14]. Different politics, law systems, and culture make the COCP risky. The COCP involves many players and strongly depends on local natural and human environments [15]. "Environmental Risk" and "Geological Risk" are ranked highest in COCP [16]. To perform well, we must understand the project delivery processes and various influence factors in the overseas markets [17].

The COCP generates opportunities to activate China's domestic economy and expand international trade and investment, especially in BRI [18]. The transport systems, especially maritime transportation, must support the COCP. China embarked on BRI to generate growth through overseas supply chain integration and infrastructure construction. However, China's business-led and elite-oriented overseas development practices created policy gaps in highrisk countries [19]. The COCP projects in BR are full of challenges. For example, the construction of the ChinaPakistan Economic Corridor (CPEC) faces challenges owing to differences between China and Pakistan in politics, economics, culture, religion, language, customs, environmental management systems, environmental protection laws, social management systems, and social management regulations [20].

2.2. Maritime Network. This study considers five research aspects related to the maritime network. First, the port and shipping stakeholders are usually investigated using game theory [21]. Collaboration and competition among port operators or shipping companies result in global logistics and supply chains $[22,23]$. In this category, generally, two main maritime stakeholders are formulated considering the network impacts as exogenous variables. Second, the hub and spoke network (HSN) is a popular networking tool in maritime port studies $[24,25]$. The HSN is an ideal structure with the effect of the economy of scale of transportation. However, although the hub and feeder ports can be identified in common sense, the network flows among a maritime network are generally aggregated from several or many shipping companies' schedules. Third, the liner shipping network consists of the maritime ports and vessel flow $[26,27]$. In this category, the maritime containers' flows or other cargo's flows are scheduled with vessel fleets and related resources. Fourth, the structures and behaviors of maritime networks can be revealed by network analysis and 
visualization methods $[4,28,29]$. Centrality analysis is a tool used widely to assess the importance of nodes in a network $[25,29,30]$. When the considered networks are massive, the network structure can be investigated by statistics. Thus, the significances of ports and maritime connections can be assessed by considering the embeddedness of them in the maritime network. In this study, network analyzing methods are also used to evaluate the significances of ports in the maritime network.

Moreover, these assessments will be coupled with the spatial distribution of the COCP. Fifth, port connectivity is examined in the contexts of cooperation [31, 32], competition, innovation, capacity [33], and supply chains [34]. The ports and their relationships can be investigated from various dimensions and aspects. In this study, COCP is a different data source and represents a new dimension. Combining the COCP and maritime network produces a new data-driven research scheme to investigate COCP in the context of BRI.

Here, six categories of data are discussed related to maritime networks. First, the port throughputs, coupled with geography data, can be studied for investigating the regional developments [35]. Port-related resource and production data are fundamental for analyzing port efficiency. Second, shipping operations data can be used to organize and schedule the vessel fleets [36] and long-run development strategies [37]. Various vessel routing, fleet, and revenue management models have been developed for shipping owners and operators' decision-making. Third, two streams of vessel data, i.e., vessel market and data of the automatic identification system (AIS), are well investigated in the literature [38]; AIS data are used for navigation, traffic distribution [39], traffic behavior [40], safety [41], and emissions studies [42]. As a typical maritime big data, AIS is used for navigation and safety of vessels. Many studies use it for safety event analysis. Recently, based on AIS, global maritime networks and shipping patterns are mined and analyzed for economic and trading issues. Fourth, cargo flow data can be extracted from port operators' cargo handling records and shipping companies' vessel flows. Time series data are a general form of cargo flow data [43]. Cargo data are more specific and meaningful for logistics and supply chains. Using cargo data and geography and economy data of ports and their hinterlands, the logistical relations and supply chains among ports can be investigated. Fifth, the casualty databases published by the International Maritime Organization (IMO) and Lloyd's [44] are conventional data sources in maritime studies. These data sources are different from AIS. They are event-based meso- or microshipping safety data, while AIS can reveal the vessel traffic and routing details in safety events. Finally, four shipping markets (the freight, sale and purchase, new building, and demolition markets) are linked by cash flows and are studied by various indices [45]. These data can reflect the shipping and vessel manufacturing markets. By coupling with other data (e.g., stock indices), it is possible to predict the market behaviors and tendencies.

As a summary, data-driven studies are few due to a lack of data sensing and acquisition systems. Various maritime networks have been devised and constructed, while few can provide global views of maritime systems with ports and flows. Among various data accessible for academic research, AIS can reflect global maritime traffic and potentially build global maritime networks. In this study, the maritime networks extracted from AIS and port profiles are coupled with COCP in the context of BRI for analyzing the patterns and behaviors in China's oversea engineering contracting.

2.3. The Belt and Road Initiative. More than 2,000 years ago, the ancient Silk Road linked China to Central Asia and the Arab world. In 2013, China government proposed establishing a network of railways, roads, pipelines, and utility grids that would link China and Central Asia, Southeast Asia, South Asia, the Middle East, Europe, and North and East Africa [46, 47]. The BRI encompasses 65 countries, accounting for roughly 32 percent of global GDP, 39 percent of global merchandise trade, and 63 percent of the world's population. China's State Council authorized an action plan in 2015 with two main components: the Silk Road Economic Belt (SREB) and the 21st century Maritime Silk Road (MSR). The SREB is envisioned as routes connecting China to Europe. China initialized the MSR to create connections among regional waterways. China seeks to take the interests of all parties into account to generate mutual benefits, including environmental management and closer cultural exchanges. While infrastructure development plays a central role, the BRI is a comprehensive one, including policy dialogue, unimpeded trade, financial support, and people-topeople exchange. The BRI involves many actors (governments, private companies, and Chinese state-owned enterprises) at many geographic scales (cities, provinces, states, and continents) [2]. China has invested at least $\$ 900$ billion ( $£ 635$ billion) in projects along with the BR, mainly in infrastructure, transport, and energy projects. The BRI has a definite developmental purpose of industrialization in the countries with a lack of infrastructure [48].

The BRI identified six major economic corridors [47], including the New Eurasian Land Bridge, China-MongoliaRussia, China-Central Asia-Western Asia, Indo-China Peninsula, China-Pakistan, and Bangladesh-China-IndiaMyanmar. These corridors will be the sites of energy and industrial clusters and represent the transportation channels, including rail, roads, waterways, air, pipelines, and information highways. The BRI may help reduce transport costs, increase trade flows, and open new markets to all affected countries, as well as promote the development of emerging industries.

The magnitude of investments anticipated under the BRI is massive. As the spearhead of BRI, the Asian Infrastructure Investment Bank (AIIB) aims to facilitate and accelerate infrastructure improvement in the region by providing capital loans and technical services. The BRI aims to improve cross-border infrastructure to reduce transportation costs across a massive geographical area between China and Europe. Improving transport infrastructure is advantageous for the IEs in the BR as far as trade creation is concerned. The AIIB creates many prominent opportunities of COCP in the 
BR. China relies on massive investment in infrastructure, roads, ports, and railways, at home and abroad, to accelerate industrial development throughout the region.

In the following, two tables (Tables 1 and 2) are compiled to reveal the research interests on BRI-related topics in Chinese and English. Table 1 shows that the number of papers having keywords of Silk Road Economic Belt (SREB), Maritime Silk Road (MSR), and Belt and Road Initiative (BRI), which were published in the Chinese Social Science Citation Index journals between 2012 and 2019. The number of papers focusing on MSR is relatively small compared with the others. Table 2 shows that the research interests in BRIrelated topics are increasing continuously.

Among the studies in Tables 1 and 2, 10 studies creating networks and using network analysis methods are identified in Table 3. The BRI was analyzed by coupling the networks, mainly using trade, investment, railway, and AIS data. Although the BRI proposed major economic corridors [47] and engineering development purposes, global engineering projects' networks are still not analyzed by combining with BRI.

\section{Research Method}

3.1. A Systematic Framework. The data sources and preprocessing programs are summarized in a flow diagram (Figure 2).

(1) The vessel flows, port facilities, and regional hierarchies are the original data source of the maritime network. The AIS data can represent the vessel flows. The port facilities include three levels of data: berths, terminals, and ports. The regional hierarchies mainly consider ports, IEs, and regions. Similarly, a region is taken as a set of IEs and takes an IE as a set of ports.

(2) The BRI would link China and Central Asia, Southeast Asia, South Asia, the Middle East, Europe, and North and East Africa [4, 46, 47]. The BR region encompasses 65 economies.

(3) In the COCP data set, each project includes the following data items: year of the contract, region, and IEs of the contracted construction, industrial sector, and subsector, and millions of dollars that indicate the importance of the project.

The maritime network formulates a holistic hierarchy from port and shipping facilities to IEs and regions, while this study connects the COCP and BR data sets with IEs. So, these three data sets can connect with the IEs. Thus, this study formulated the embodied maritime network.

Based on the embodied maritime network and three data sets, this study conducted two streams of analysis: timespatial distribution and network centrality. The time distribution analysis uses the annual data of COCP. By projecting the COCP onto the maritime network, this study investigated the spatial distribution. Here, two representative kinds of centralities are examined for IEs: degree centrality and PageRank centrality. The primary purpose is to rank the IEs in maritime flow or COCP. This examined the differences in spatial distributions of IEs under different centralities and the relations among COCP, BRI, and maritime networks extensively.

3.2. Data-Driven Network Analyzing Method. This study developed the data-driven analytics method under the following considerations. First, the maritime network, coupled with the COCP and BRI, forms a new embodied maritime network. Second, the time-spatial patterns of COCP are examined upon the embodied network. The COCP from 2005 to 2017 provides a time series of data. Third, the centrality and spatial analysis are used to examine the relations among the maritime network, COCP, and BRI. Figure 3 presents the data flows.

3.2.1. Network Formulation. The maritime network is defined by a set of berths, and the vessel flows among the berths $($ Berth Net=(Berth, flow) $)$ based on the data system developed. Berth, terminal, maritime port, and IE are four levels of geography entities. So, we can roll up the BerthNet to TerminalNet, PortNet, and IENet (IENet=(IE, flow)). We use the IENet in coupling relations among COCP, maritime network, and BR. By connecting the countries in COCP, $\mathrm{BR}$, and IEs, based on the IENet, we can get the COCPNet and BRNet. These networks share the same set of IEs and constitute an embodied network. Notably, in COCPNet and $B R N e t$, the connections are represented by Boolean matrices a component of which is True when the corresponding flow in the IENet is positive; otherwise, False. Additionally, this study used the subnetworks containing connections to China in the analysis in the following sections.

3.2.2. Centrality Analysis. Centrality measures originated from social network analysis are used to rank the node importance in complex networks. Degree centrality represents the number (or weighted number) of connections upon a node. This study can interpret the degree in throughput in a flow network, e.g., vessel flow network. The degree centrality of a node $v \in V$ of the network $N=(V, E)$ is denoted by $C^{D}(v)$.

Eigenvector centrality is a measure of the influence of a node in a network. Google's PageRank is a variant of the eigenvector centrality. Let $A_{\mathrm{vt}} \in\{0,1\}$ be the adjacency matrix. The relative centrality score of node $v$ is $C^{P}(v)$ given in the following, where $M(v)$ is a set of neighbors of $v$ and $\lambda$ is a constant:

$$
C^{P}(v)=x_{v}=\frac{1}{\lambda} \sum_{t \in M(v)} x_{t}=\frac{1}{\lambda} \sum_{t \in V} A_{\mathrm{vt}} x_{t} .
$$

In general, this equation can be reformulated by $\mathrm{Ax}=\lambda x$. Here, many candidate values of $\lambda$ may exist. In the PageRank centrality, $C^{P}(v)$ is further reformulated as follows, where $L(u)$ is the number of neighbors of node $u$ and given in the following: 
TABLE 1: Number of papers on the Belt and Road in China's CSSCI journals.

\begin{tabular}{|c|c|c|c|c|c|c|c|c|c|}
\hline \multirow{2}{*}{ Keywords } & \multicolumn{9}{|c|}{ Number of papers } \\
\hline & 2012 & 2013 & 2014 & 2015 & 2016 & 2017 & 2018 & 2019 & Sum \\
\hline Silk Road Economic Belt (SREB) & 2 & 10 & 163 & 329 & 280 & 177 & 89 & 60 & 1110 \\
\hline Maritime Silk Road (MSR) & 4 & 6 & 43 & 153 & 133 & 110 & 81 & 57 & 587 \\
\hline Belt and Road Initiative (BRI) & - & - & 32 & 874 & 1429 & 2207 & 1653 & 2171 & 8366 \\
\hline Sum & 6 & 16 & 210 & 1196 & 1736 & 2373 & 1781 & 2246 & 9564 \\
\hline
\end{tabular}

Source: Chinese Social Science Citation Index (CSSCI) (2020).

TABLE 2: Number of papers on the Belt and Road in SSCI/SCI/SCIE journals.

\begin{tabular}{|c|c|c|c|c|c|c|c|c|c|}
\hline \multirow{2}{*}{ Keywords } & \multicolumn{9}{|c|}{ Number of papers } \\
\hline & 2012 & 2013 & 2014 & 2015 & 2016 & 2017 & 2018 & 2019 & Sum \\
\hline Silk Road Economic Belt (SREB) & - & - & - & 3 & 17 & 23 & 47 & 54 & 144 \\
\hline Maritime Silk Road (MSR) & - & 2 & 3 & 2 & 6 & 20 & 45 & 56 & 134 \\
\hline Belt and Road Initiative (BRI) & 17 & 13 & 15 & 17 & 38 & 78 & 216 & 347 & 741 \\
\hline Sum & 17 & 15 & 18 & 21 & 52 & 98 & 247 & 379 & 847 \\
\hline
\end{tabular}

Source: Web of Science (2020).

TABLE 3: BRI-related studies using network analyzing methods.

\begin{tabular}{lcc}
\hline Study topics & Network and data & Analyzing method \\
\hline Trade relationships [32] & Trade data & Connectivity \\
Trade cooperation [23] & China's export trade data & Connectivity \\
China-Vietnam maritime flows [29] & AIS and port data & Network and time series \\
Interactions between ports [25] & AIS and port data & Centrality and connectivity \\
FDI analysis [49] & FDI network & Spatial analysis \\
Bulk trade analysis [50] & Bulk trade and AIS data & Centrality \\
Crude oil trade [51] & Trade and GDP data & Centrality and connectivity \\
Shipping vulnerability [52] & Liners' schedules & Vulnerability analysis \\
Ranking nodes in CRE & CRE network & Centrality analysis \\
CRE consolidation & CRE network & Connectivity analysis \\
\hline
\end{tabular}

Note. CRE $=$ China Railway Express; FDI $=$ foreign direct investment; GDP $=$ gross domestic product.

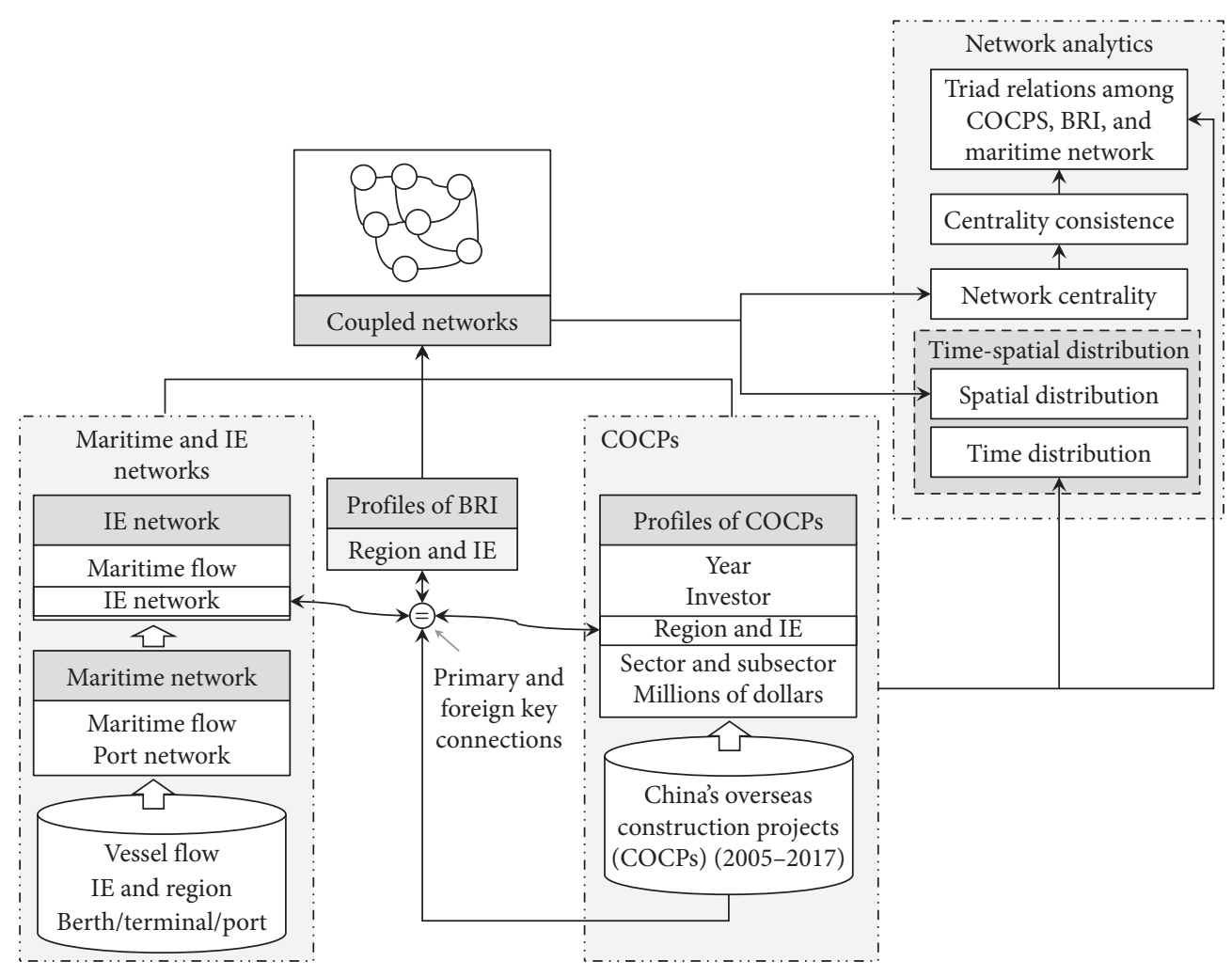

FIgURE 2: The systemic analyzing framework. 


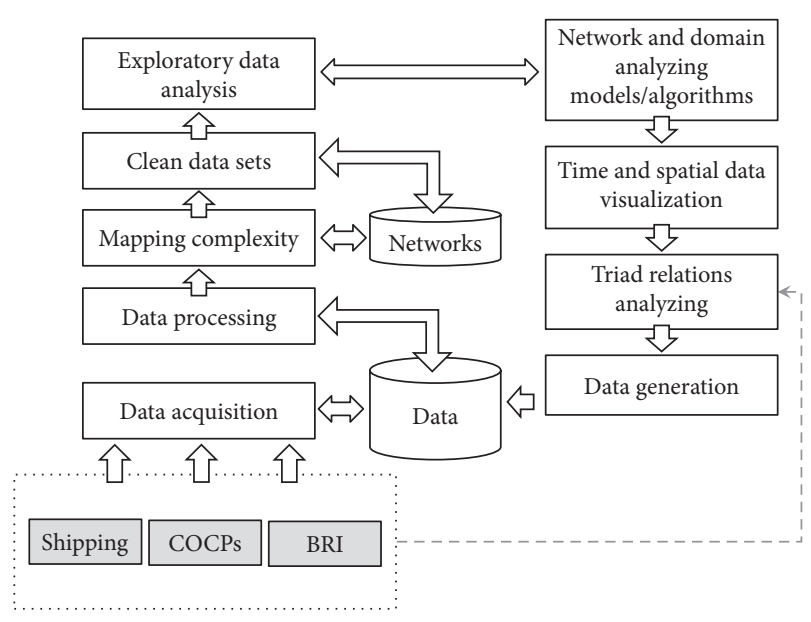

Figure 3: The data-driven analyzing method.

$$
\begin{aligned}
C^{P}(v) & =x_{v}=\alpha \sum_{u} \frac{A_{\mathrm{uv}} x_{u}}{L(u)}+\frac{1-\alpha}{|V|}, \\
L(u) & =\sum_{v} A_{\mathrm{uv}} \cdot
\end{aligned}
$$

Compared with eigenvector centrality, the scaling factor $L(u)$ is introduced.

\section{Data}

4.1. China's Overseas Construction. The COCP data set includes 1396 large transactions across energy, technology, transportation, and other industries [5]. Each transaction consists of the amount, Chinese parent company, host country, and sector. This study uses six columns of the data table: year, quantity in millions, sector, subsector, country, and region. A list of 65 IEs in BR is used to classify the data records by the country column into two sets: in BR and out of BR.

4.2. Maritime Network. This study used three data sources. First, the "Shipping Earth Project" [4, 53] provides the data on the maritime network. Figures 4 and 5 present the detailed data structures and entity relations. To compute the flows among IEs, this study generated three levels of networks (maritime traffic network, port flow network, and IE flow network). This study generated the maritime flow network from the data in 2016. This study tested and compared data of 2013-2016 years and found that the differences in network structure are not significant. To analyze the BRI impacts, this study used a list of 65 BR IEs.

This study had collected the following data: $130,000,000,000$ records of vessel positions for 3,000,000 MMSI numbers (generally an MMSI number represents a vessel); summary profiles of 300,000 vessels and detailed profiles of 100,000 vessels; and 45,000 records for berths, terminals, and ports. The raw and generated data in processing account for above $20,000 \mathrm{~Gb}$. A multiplex network is generated from a big data system (Figures 2 and 3 ).

\section{Results}

Table 4 presents the purposes, data sets, and analytical steps of analytical experiments. In Figure 6, the relations between these experiments and the network analysis methods are connected. For example, the triad relations among BRI, COCP, and maritime networks are reflected primarily in Experiments 3, 4, and 7. In the following, the results of the ten experiments are visualized and analyzed.

5.1. Top IEs Contracted with China. The overall ranking results of the top 20 IEs contracted with China are presented in Figure 7. This study can rank thirteen BR IEs in the top 20 IEs; in Figure 8, in 2005-2007, 12 are in the top 20 and then 13 are in the top 20 in 2015-2017. From these three diagrams of the top 20 IEs contracted with China, the BR and Africa are the focuses of COCP although the top IEs have changed to some extends in these 13 years. Recently after China initiated the BRI, Pakistan and Bangladesh represent the China-Pakistan Economic Corridor and the BangladeshChina-India-Myanmar Economic Corridor [1] individually. In this aspect, the COCP is severely affected by the BRI. Also, COCP in Africa is prominent. So, Africa will be under the shed of BRI in the future.

5.2. Regional Distributions. Figures 9 and 10 depict the regional distributions of the COCP. In Figure 9, this study identified three key regions: West Asia and East Asia, subSaharan Africa, and the Arab Middle East and North Africa. The results are consistent with Figures 7 and 8 that BR and Africa are the most critical contracted regions. In Figure 10, from 2005-2007 to 2015-2017, the most contracted regions shift from the BR region to extended markets (sub-Saharan Africa and South America); some increase can be observed in the USA. However, the BR region is still a hot target of COCP. Apart from East and West Asia, Middle Asia should be a new focus when the BRI functions continuously.

5.3. Sector Distributions. Figure 11 depicts the overall section distribution. The energy and transport dominate the most important sectors, and the real estate sector also performs well. These results can be explained tentatively as follows: China is short of energy; China's manufacture and trade development make it eager for import and export through cross-border transportation.

From 2005-2007 to 2015-2017 (Figure 12), two noticeable changes can be observed: the expansion in the transport sector and concession in the metal sector. In China and even globally, the steel industry is mature and oversupplied, which will decrease the COCP contracts. In BRI, railway and seaborne transport facilities should be propelled by China in the COCP. So, the transport sector contracts are booming in recent years. 


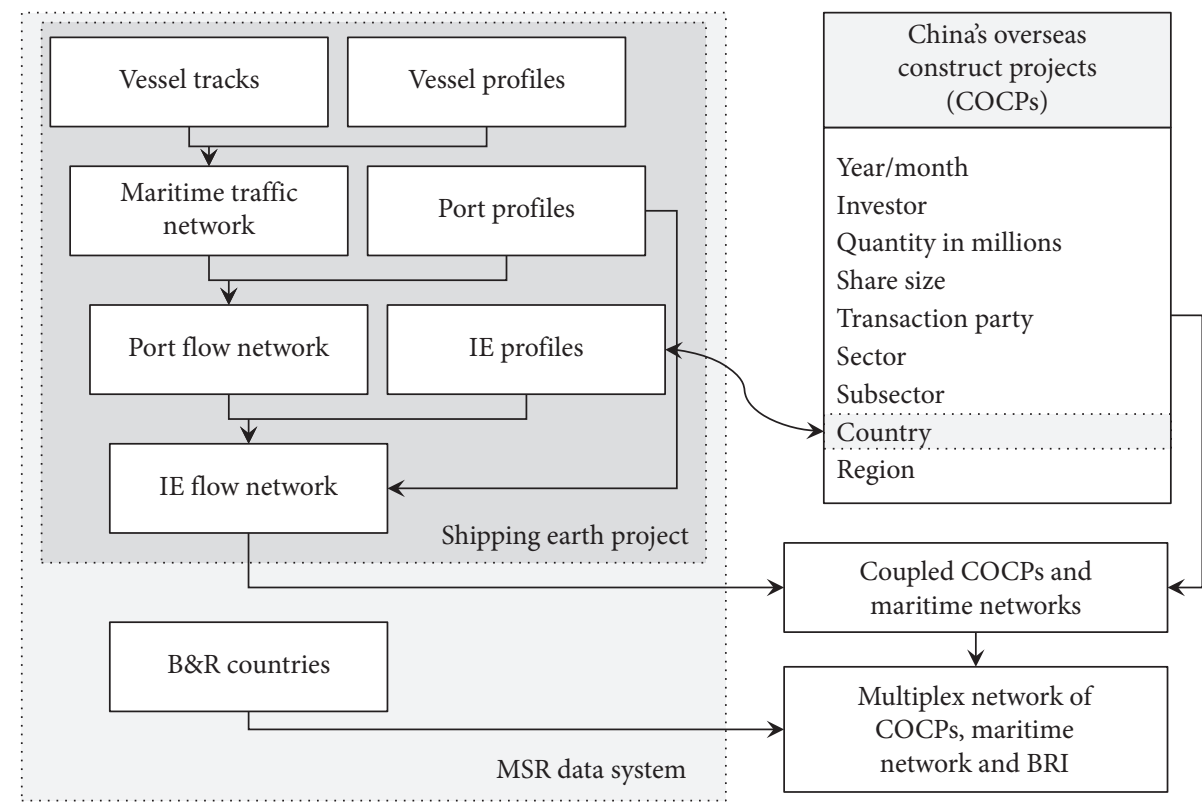

Figure 4: A maritime network based on port network and vessel flows.

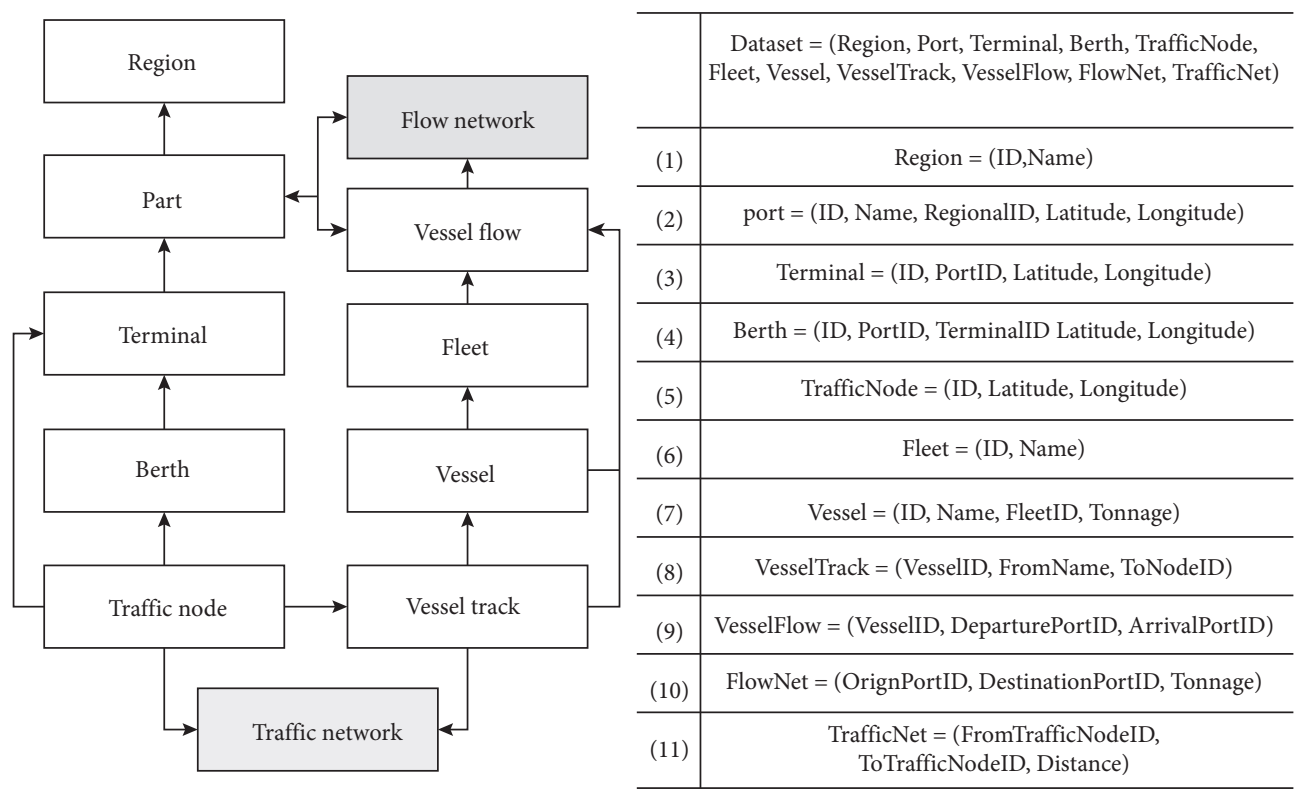

FIgURE 5: Data structures in the shipping earth project.

5.4. Spatial Distribution. By using the 13 years' data of COCP, Figure 13 portrays the spatial distribution. In the visual IE circles, three belts and one point have emerged as the general tendency of the COCP. Three belts can be observed: BR, Africa, and South America. The first two are dominant. One point refers to Australia.

Figure 14 depicts the evolution and tendency from 2005-2007 to 2015-2017. Ten years ago, the COCP was mainly contracted with the IEs in BR at that time; this status is kept in the following ten years, while two new markets emerge: Africa and South America. So, three main belts can be identified in the past ten years.

5.5. Annual COCP Projects in Landlocked and Maritime IEs. This study divided the IEs into two groups, landlocked and maritime IEs. If an IE has at least one maritime port, this study takes it as a maritime IE; otherwise, it is landlocked. Figure 15 depicts the annual and accumulated countries and millions of dollars. It can be concluded that the maritime IEs 
TABLE 4: Settings of the analytical experiments.

\begin{tabular}{|c|c|c|c|c|}
\hline No. & Purpose & Data & Analytical steps & Result \\
\hline 1 & Top IEs contracted with China & $\begin{array}{l}\text { COCP } \\
\text { MN } \\
\text { BRI }\end{array}$ & $\begin{array}{l}\text { (1) Aggregate millions of dollars of the COCPs data by IEs and rank the IEs } \\
\text { (2) Visualize the IEs in a world map } \\
\text { (3) Examine the IEs in BR } \\
\text { (4) Apply step } 1 \text { to the COCPs data of 2005-2007 } \\
\text { (5) Apply step } 1 \text { to the COCPs data of 2015-2017 }\end{array}$ & $\begin{array}{l}\text { Figure } 7 \\
\text { Figure } 8\end{array}$ \\
\hline 2 & Regional distribution & COCP & $\begin{array}{l}\text { (1) Aggregate millions of dollars the COCPs data by regions } \\
\text { (2) Apply step } 1 \text { to the COCPs data of 2005-2007 } \\
\text { (3) Apply step } 1 \text { to the COCPs data of 2015-2017 }\end{array}$ & $\begin{array}{l}\text { Figure } 9 \\
\text { Figure } 10\end{array}$ \\
\hline 3 & Sector distribution & COCP & $\begin{array}{l}\text { (1) Aggregate millions of dollars the COCPs data by sectors } \\
\text { (2) Apply step } 1 \text { to the COCPs data of } 2005-2007 \\
\text { (3) Apply step } 1 \text { to the COCPs data of } 2015-2017\end{array}$ & $\begin{array}{l}\text { Figure } 11 \\
\text { Figure } 12\end{array}$ \\
\hline 4 & COCP spatial distribution & $\begin{array}{l}\text { COCP } \\
\text { MN } \\
\text { BRI }\end{array}$ & $\begin{array}{l}\text { (1) Aggregate millions of dollars of the COCPs data by IEs and rank the IEs } \\
\text { (2) Visualize the IEs in a world map } \\
\text { (3) Examine the spatial distribution patterns of IEs } \\
\text { (4) Apply steps } 1-3 \text { to the COCPs data of } 2005-2007 \\
\text { (5) Apply steps } 1-3 \text { to the COCPs data }\end{array}$ & $\begin{array}{l}\text { Figure } 13 \\
\text { Figure } 14\end{array}$ \\
\hline
\end{tabular}

(1) Identify the IEs (landlocked and maritime) by using MN (where a landlocked

IE has no maritime port)

(2) Aggregate millions of dollars of the COCPs data by year and IE types

5

Annual COCP in landlocked and maritime IEs

COCP (landlocked or maritime)

MN (3) Aggregate IE numbers of the COCPs data by year and IE types (landlocked or maritime)

(4) Visualize the annual (annual accumulated) millions of dollars (countries) by bar diagrams

(1) The IEs are classified into ones in BR and ones out of BR

(2) Aggregate millions of dollars of the COCPs data by year and IE types (in or out of BR)

6 Annual

Annual COCP in or out of the COCP

(3) Aggregate IE numbers of the COCPs data by year and IE types (in or out of Figure 16 BRI BR)

(4) Visualize the annual (annual accumulated) millions of dollars (countries) by bar diagrams

(1) Aggregate millions of dollars of the COCPs data by IEs

(2) Compute the degree and PageRank centralities of IEs in the maritime

$7 \quad$ COCP and network spatial relation COCP network

MN (3) Visualize the IEs in grey color and the IEs with COCP in yellow color while Figure 17 BRI the circle sizes for IEs represent the centrality values

(4) Visualize the IEs connected with China in the maritime network by the same settings as step 3

(1) Choose the records in COCPs where the sector is transport

$\begin{array}{ll}\text { COCP } & \text { (2) Aggregate the data by millions of dollars and the subsectors } \\ \text { MN } & \text { (3) Vis }\end{array}$

8 Transport sector distribution $\mathrm{MN}$

BRI (3) Visualize the spatial distrib

(1) Choose the records in COCPs where the subsector is shipping

COCP (2) Aggregate the data by millions of dollars

9 Shipping sector distribution

MN (3) Visualize the spatial distribution of transport contracts on a world map

BRI (4) Using the above data and the steps in Experiment No. 6, depict the annual

Figure 19 COCP in the shipping sector

Note. $\mathrm{MN}=$ maritime network.

are popular in COCP. The number of affected countries and "millions of dollars" both reach their peaks in 2015. Most maritime IEs also can be explained by the bulk and cheap maritime transport system. In another perspective, the landlocked IEs are potential markets, especially in railway construction projects.
5.6. Annual COCP Projects in or Out of the BR IEs. This study analyzes the IEs in and out of BR by annual "millions of dollars" and contracting countries. Also, Figure 16 depicts the annual and accumulated annual values. In Figures 16(b) and $16(\mathrm{~d})$, the importance of the BR's IEs is prominent compared with other contracted IEs. Like the results of 


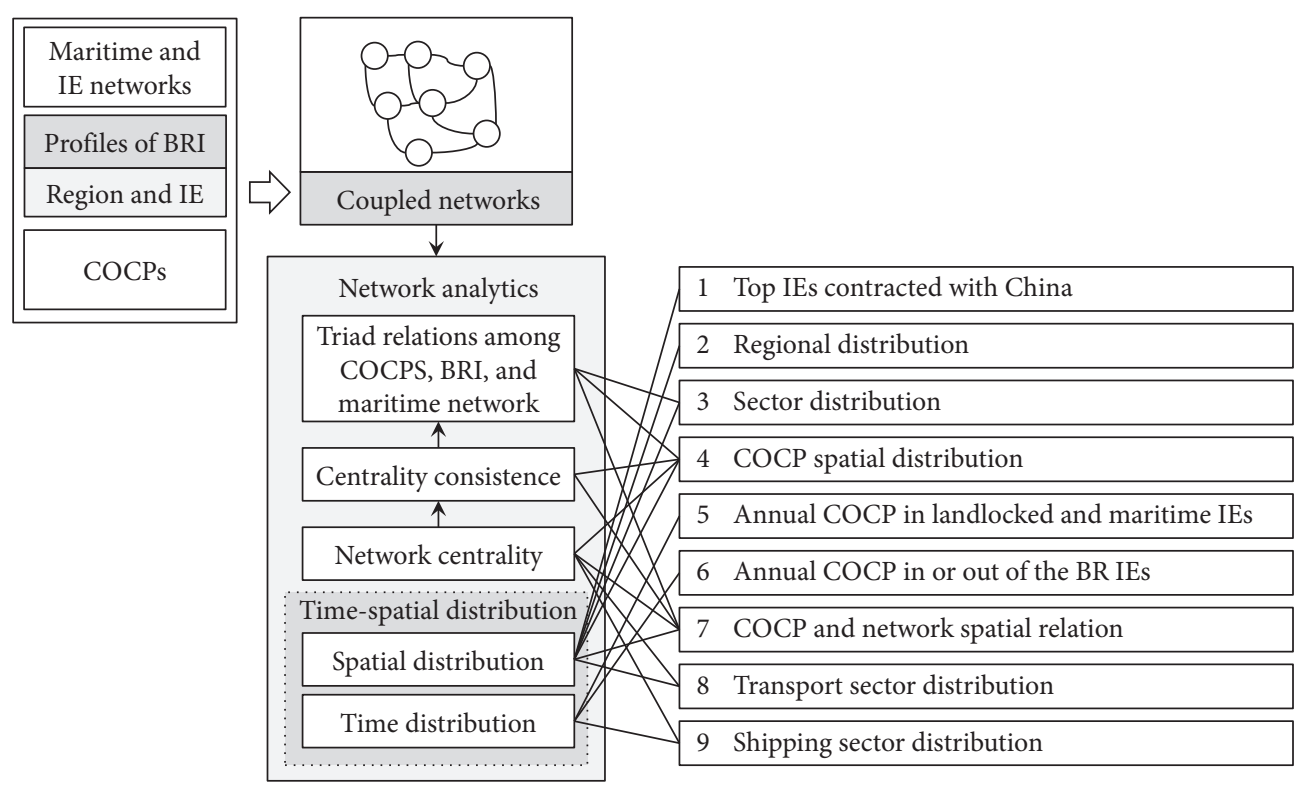

FIgURe 6: The systemic analyzing framework.

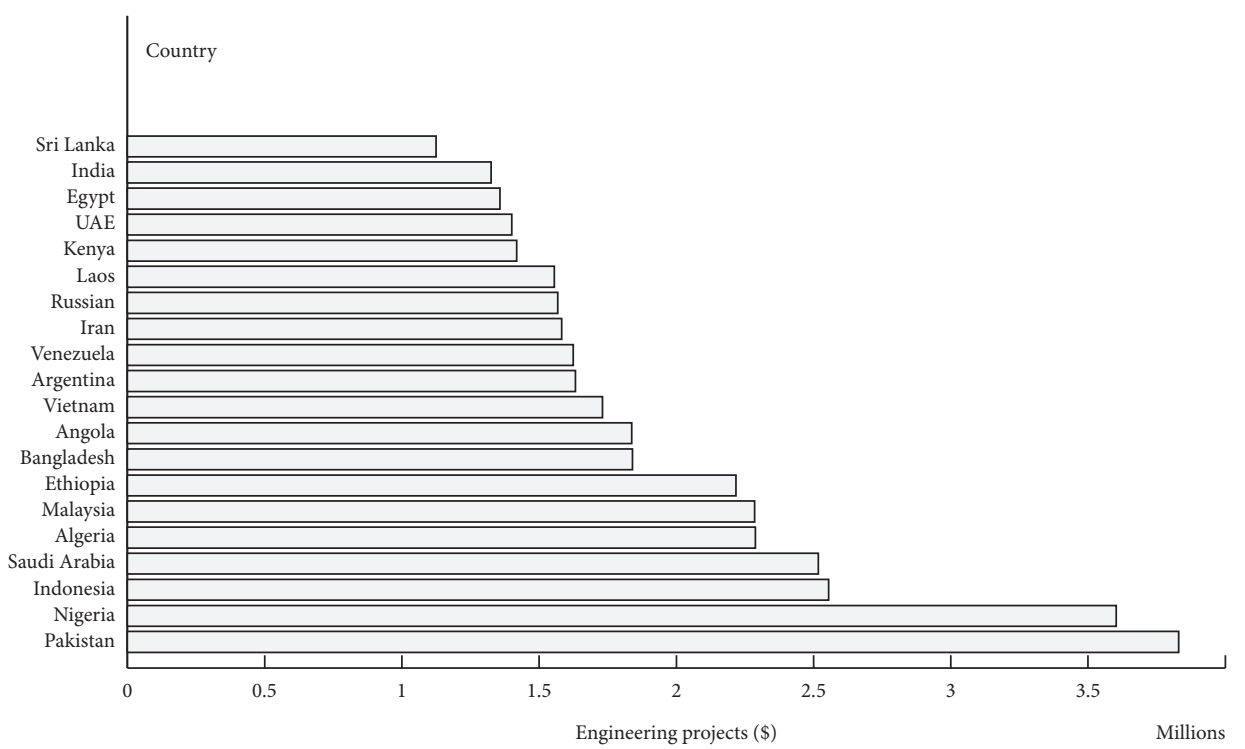

FIgure 7: Top 20 IEs with COCP (2005-2017) (E1).

analyzing annual COCP in landlocked and maritime IEs, the contracted value got its peak in 2015, and the incremental tendency of the BR's IEs is explicit (Figure 16(b)). Based on these results, South America should be the most potential region for COCP soon.

5.7. COCP and Maritime Network Spatial Relation. This analysis is conducted precisely to reveal the relation between COCP and the maritime network. Degree and PageRank centralities are chosen and examined. In Figures 17(a) and 17(b), the circles represent the IEs while their sizes represent the scaled values of the centrality values; and the grey color circles indicate general IEs while the yellow ones are IEs contracted with China in COCP. Although these two centralities are different, in these two diagrams, the differences are not explicit. The IEs that have COCP contracts with China are mostly of high centrality values. Most importantly, two potential COCP markets can be identified, as presented as two belts in Figures 17(a) and 17(b): (1) the Caribbean Sea and (2) Western Europe and North Africa.

In Figure 17(c), the sizes of the circles represent the throughput of the IEs with China. The IEs with secure maritime connections with China also have COCP contracts with China. Furthermore, the Caribbean Sea, Western Europe, and North Africa should be potential COCP markets. 


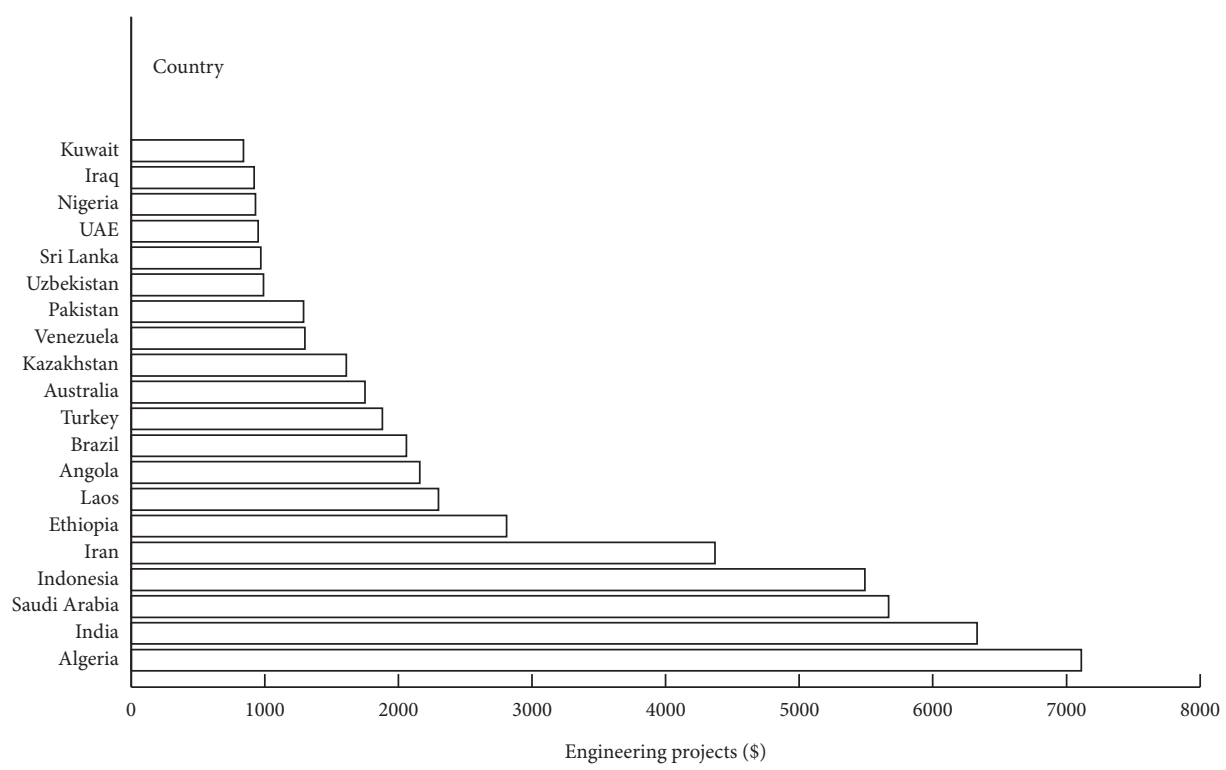

(a)

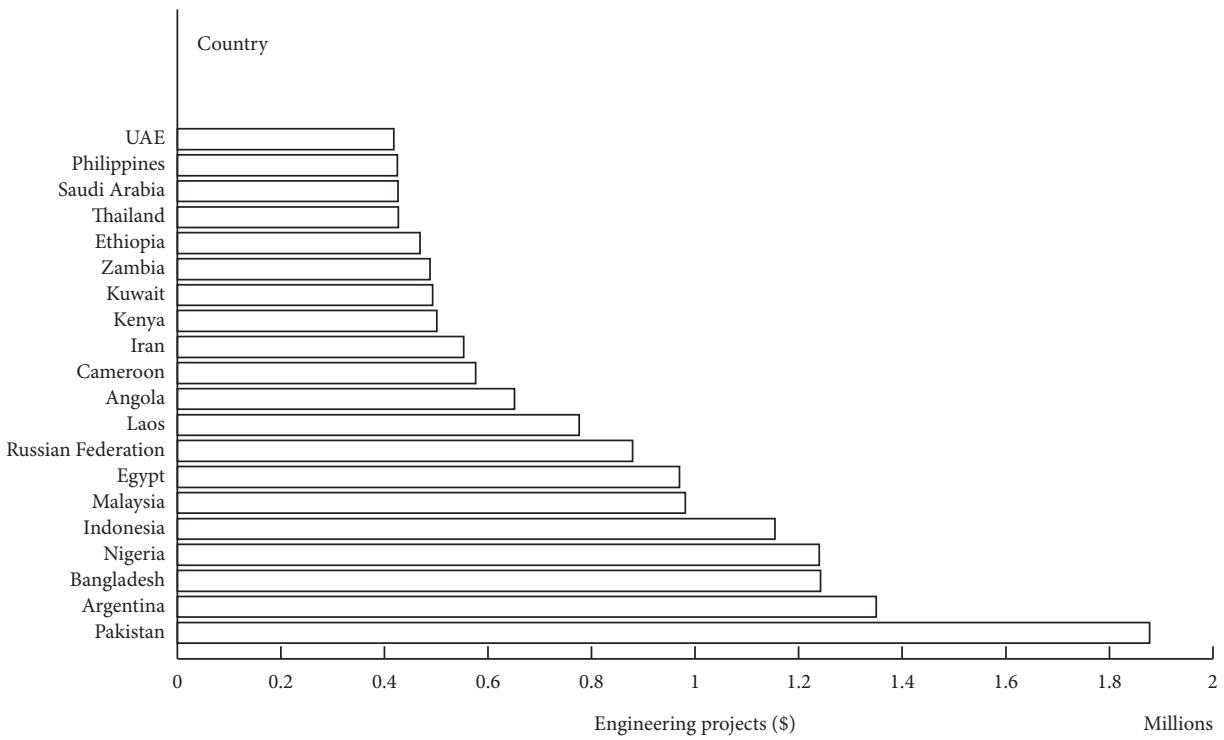

(b)

FIgURE 8: Top 20 IEs of China's overseas construction projects (E1): (a) 2005-2007; (b) 2015-2017.

5.8. Transport Sector Distribution. As studied above, the transport sector is prosperous in COCP, and the transport system is also a way for China to "go out." The COCP can be investigated in the transport sector in Figure 18. From the spatial distribution of transport COCP in Figure 18(a), we can identify two central regions: BR and Africa. Looking into Figure 18(b), it can be further investigated: road and rail transport projects mainly locate in Africa while the shipping projects are mainly along the MSR. When the BRI can achieve its purposes, it will strengthen the MSR, and the SREB will demand many road and railway constructions. America will be a potential market of COCP, especially in the shipping sector.
5.9. Shipping Sector Distribution. Although the shipping sector just accounts for a minor portion of the whole COCP projects, the COCP projects are consistent with the maritime network. Figure 19 depicts the shipping COCP spatially. Three explicit clusters can be observed on the map: the MSR, sub-Saharan Africa, and the Caribbean Sea. The Caribbean Sea is a distinct but minor cluster. The MSR represents the mature market of China's industries, while Africa should be an emerging market. The Caribbean Sea involves a virtual channel between China and West Europe, as well as America. So, the shipping sector in the COCP is well consistent with the global market of Chinese industries and products. 


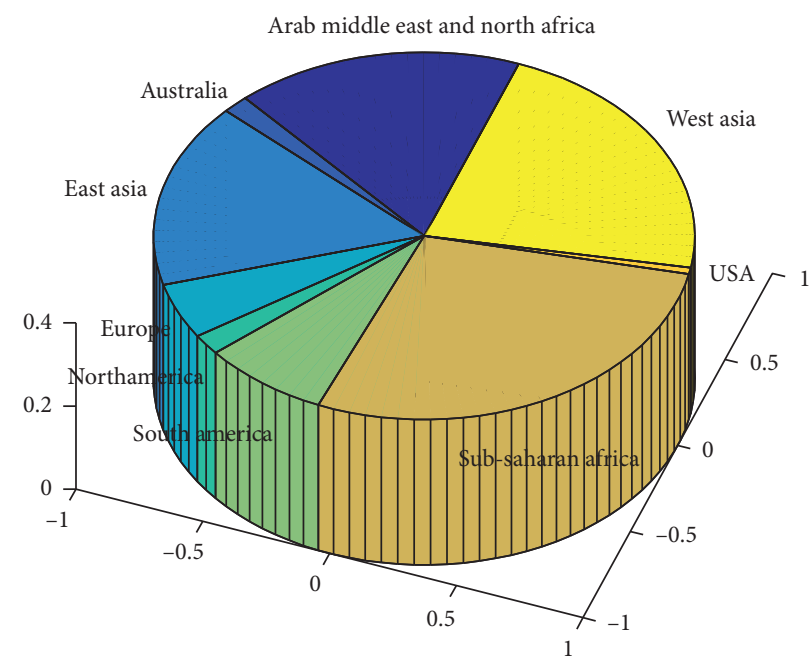

FIgURE 9: Overall regional distribution (2005-2017) (No. 2).

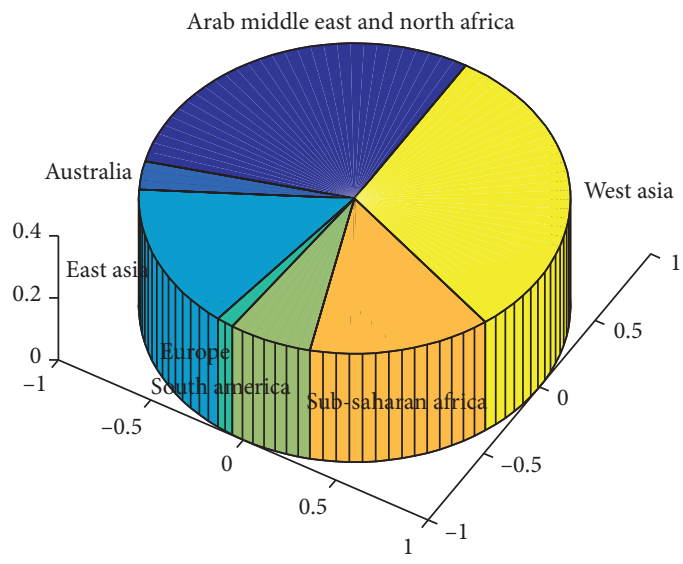

(a)

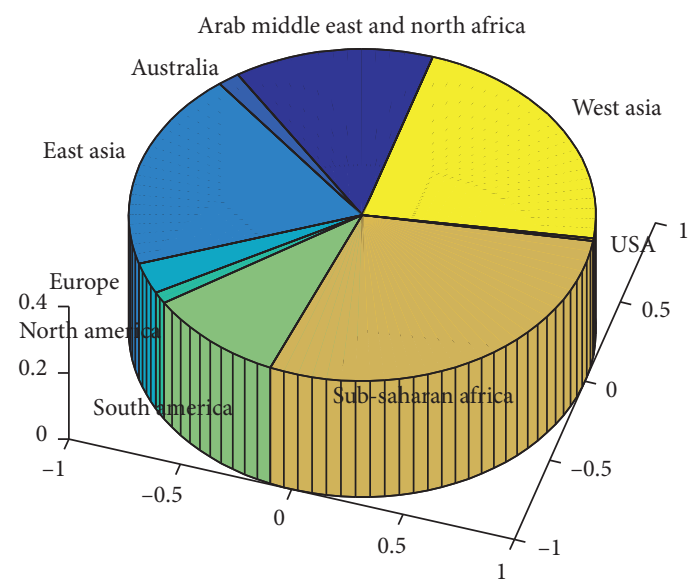

(b)

Figure 10: Regions of China's overseas construction projects (No. 2): (a) 2005-2007; (b) 2015-2017.

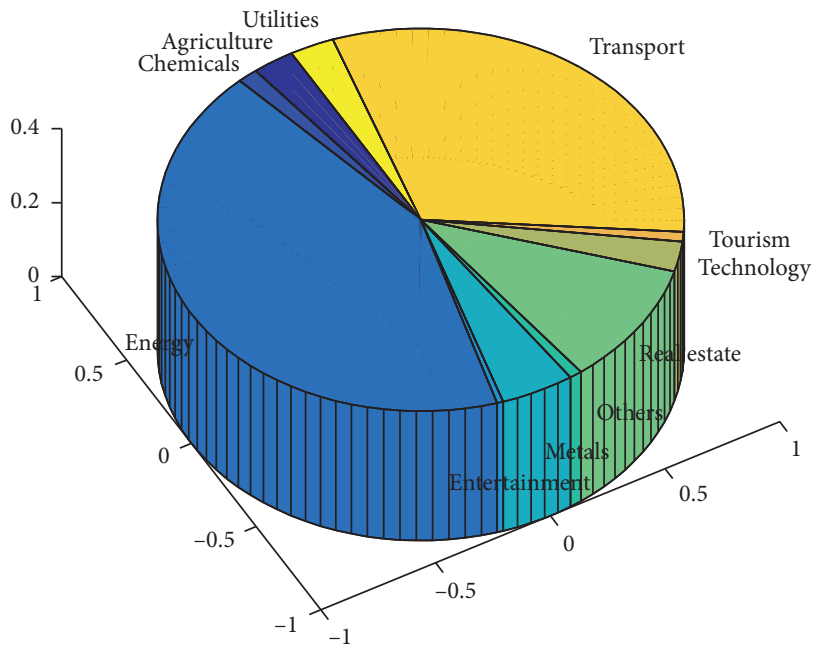

FIgURE 11: Overall sectional distribution (2005-2017) (No. 3). 


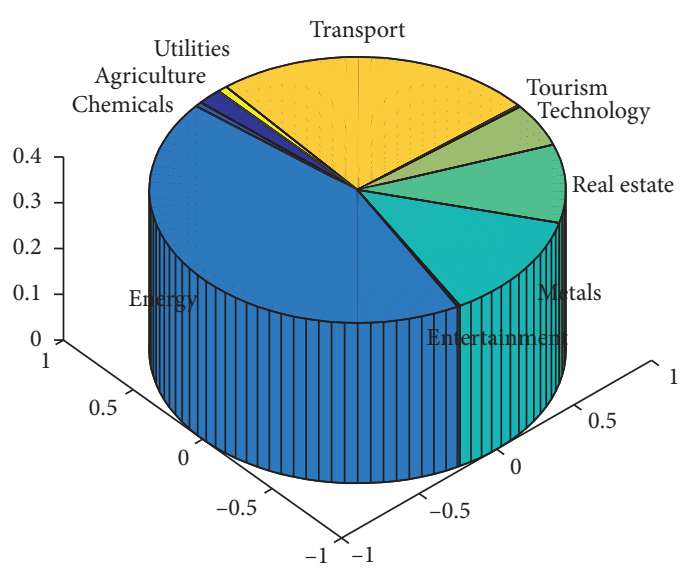

(a)

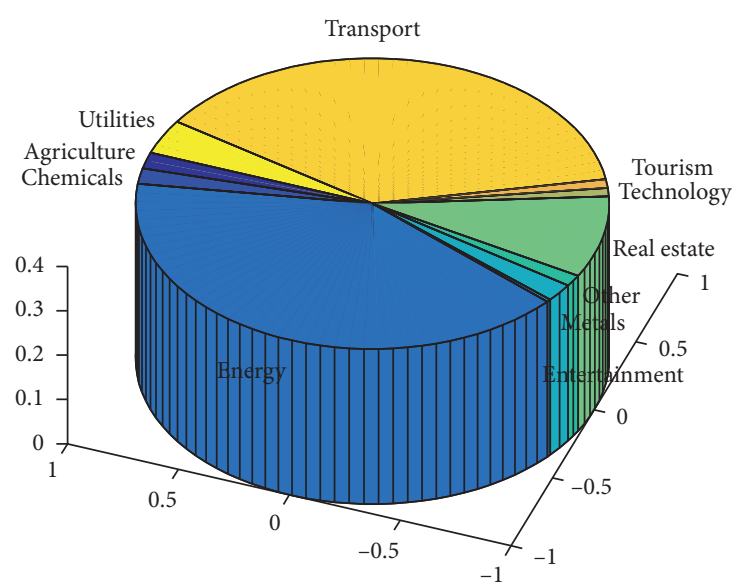

(b)

Figure 12: Sectors of China's overseas construction projects (No. 3): (a) 2005-2007; (b) 2015-2017.

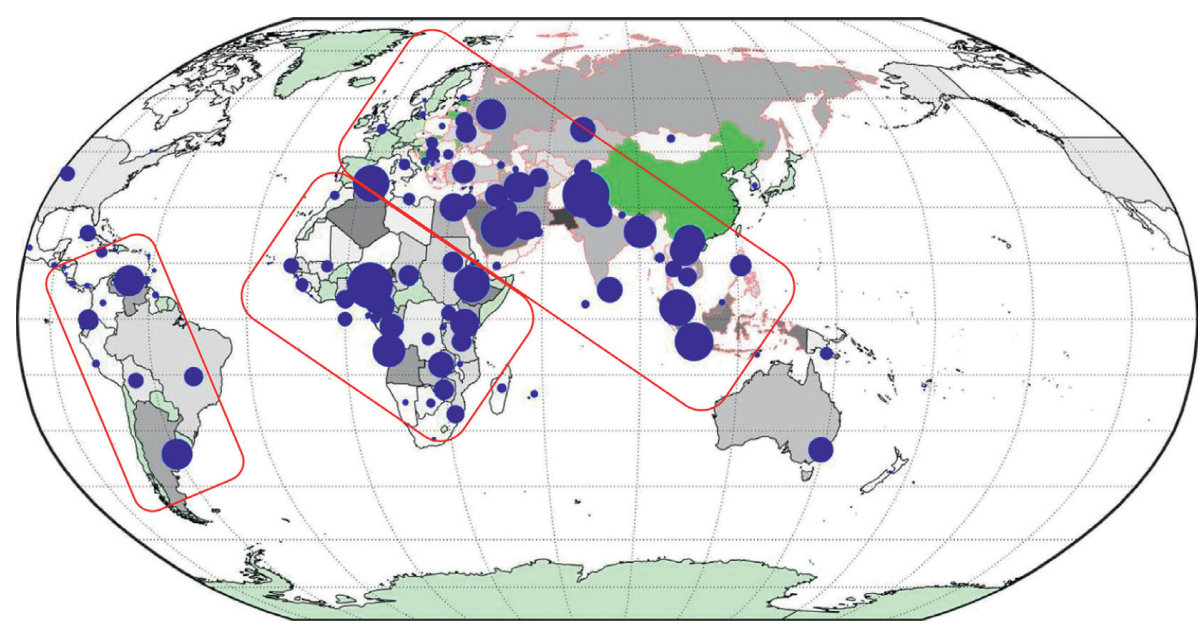

FIgURE 13: Spatial distribution of COCP (2005-2017) (No. 4).

Figure 20 depicts the annual data on contracted values and countries. The BR IEs dominate the shipping COCP in values (millions of dollars) while more IEs out of BR have shipping construction contracts with China. In this aspect, the COCP tends to serve the global maritime network.

\section{Discussion}

Coupling the COCP, maritime network, and BRI, this study conducted a series of data-driven analytical experiments to reveal the tendencies and opportunities of COCP and the extendable investment, trading, and geo-economics possibilities. Some generations are made as follows:

(1) Based on the analytical results on time and spatial distributions and evolutions, this study can observe some focuses of COCP in a long time and can also observe some variants, especially in the context of BRI. The MSR and sub-Saharan Africa are the central regions of COCP in these 13 years. New markets begin to shape, and potential markets emerge. Some big COCP projects are critically in line with BRI. The most important result that the dominant position of the $\mathrm{BR}$ region in COCP had emerged ten years ago before China initialized the BRI. In this aspect, the BRI evolves from China's overseas business activities, and it is an upgrade of China's international business. Many international scholars are suspicious about and even criticize the BRI because it indicates China's geopolitical ambitions [2, 14, 20]. However, the results of this study reveal that the BRI is in line with the global maritime network, and the COCP proceeds much earlier than BRI. The impacts and contributions of BRI to Eurasia and even the world should be further examined.

(2) Based on the sectors and spatial distribution of COCP and the relations of maritime network and COCP, the functions of COCP can be summarized as follows. First, COCP projects are supplements to China's domestic energy shortage and industrial structure. Second, China's "go out" strategy explicitly affected or even propelled the COCP so that the transport infrastructures are primary targets of 


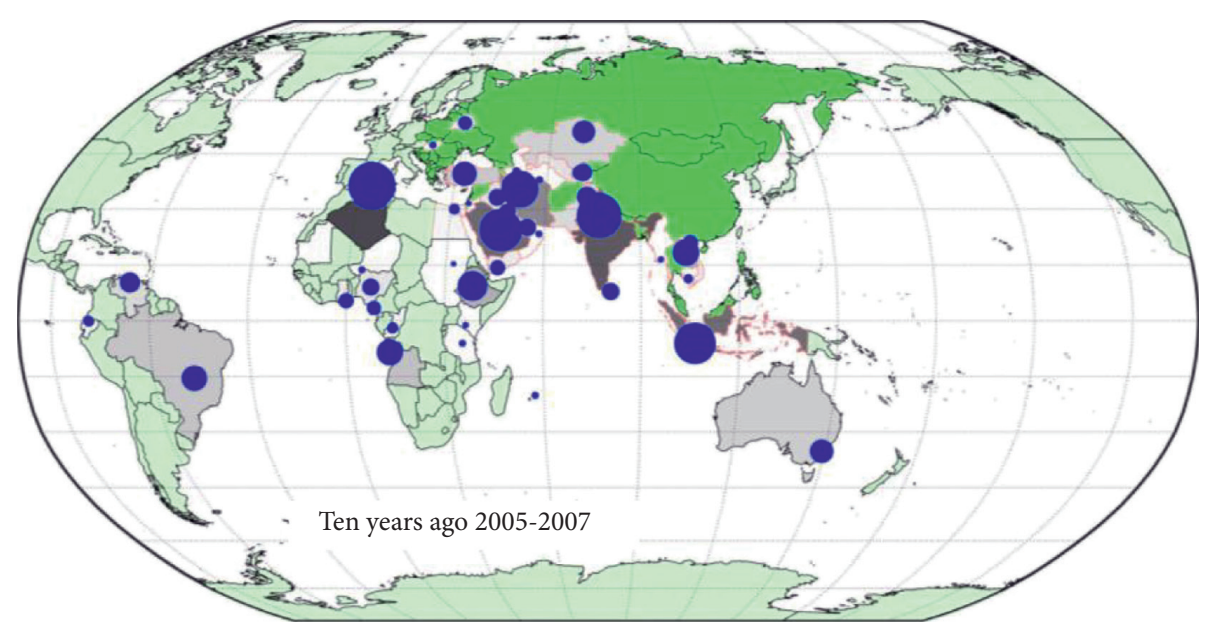

(a)

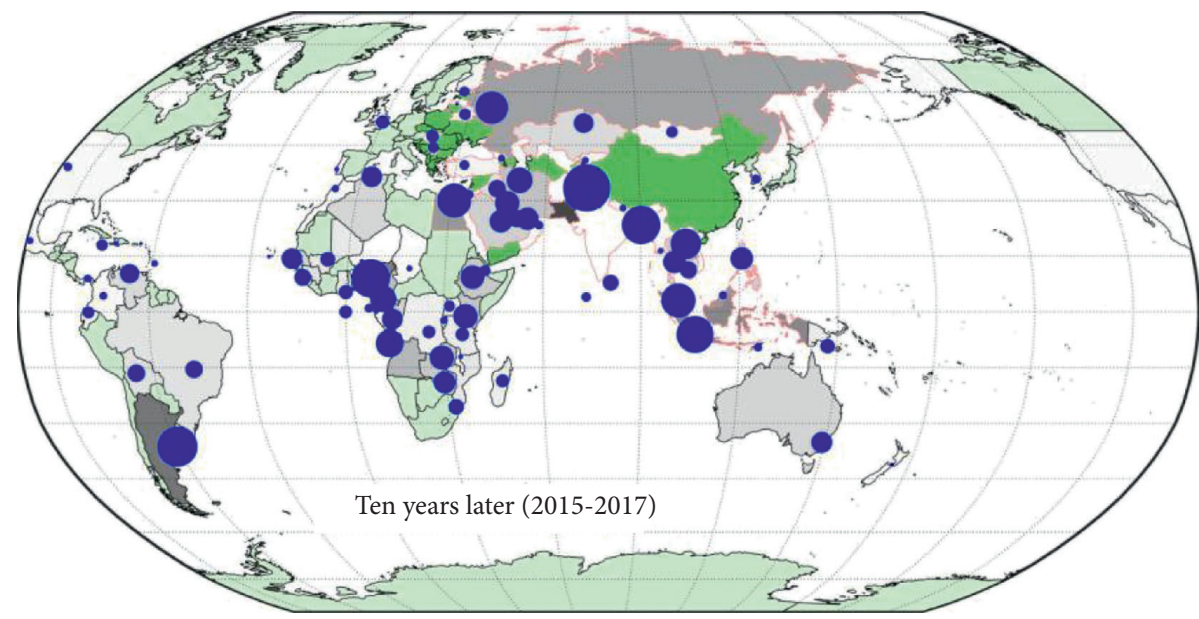

(b)

Figure 14: Changes in China's overseas construction projects' spatial distribution (No. 4): (a) 2005-2007; (b) $2015-2017$.

COCP. Third, although the development of COCP is mainly a way to upgrade China's industries, it is also in line with the global maritime network, indicating global trade and economy. Considering these points, the BRI will further strengthen the COCP because of its ties to China and the world. In summary, the COCP projects have three functions: domestic industrial supplements and upgrade, potential market, and BRI developments. The COCP spatial distribution reveals that the BR especially the MSR and sub-Saharan Africa are hot regions; the SREB (mainly containing landlocked IEs), North Africa, and South America should be potential targets of COCP. In other words, the BR and Africa as close continents are most markets of COCP, while America IEs will also be potential contractors. The BRI brings various and multidimensional impacts on the economy, trade, and international relationships [54]. Due to the consistent relations between COCP and BRI, as revealed, this study asserts that the $\mathrm{BRI}$ and $\mathrm{COCP}$ can find development opportunities by considering each other's time and spatial tendencies.

(3) Comparing with maritime IEs, COCP contributes less to landlocked IEs. The COCP projects are infrastructures and possibly restricted by the transport system. So, the developments of COCP can enhance the infrastructures of landlocked IEs. In this aspect, the BRI caters to this requirement. As expected, the landlocked IEs in Eurasia will release secure construction contracts when the BRI can function [55]. Due to the COCP in Africa and especially the COCP in the transport sector, the landlocked IEs in Africa will generate great possibilities for construction contracts. The BR IEs contribute much to the COCP, comparing the IEs out of BR. The peak located in 2015 and these trends will continue for a period. Considering the COCP history and increase in Africa and the geographical closeness between Africa and Eurasia, Africa will generate the most increment for the COCP in the context of BRI. However, China will also face challenges in oversea engineering projects 


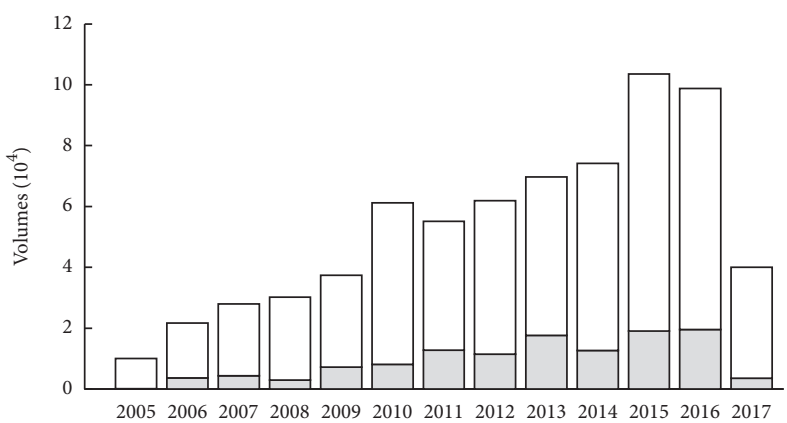

Year

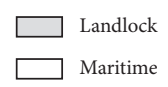

(a)

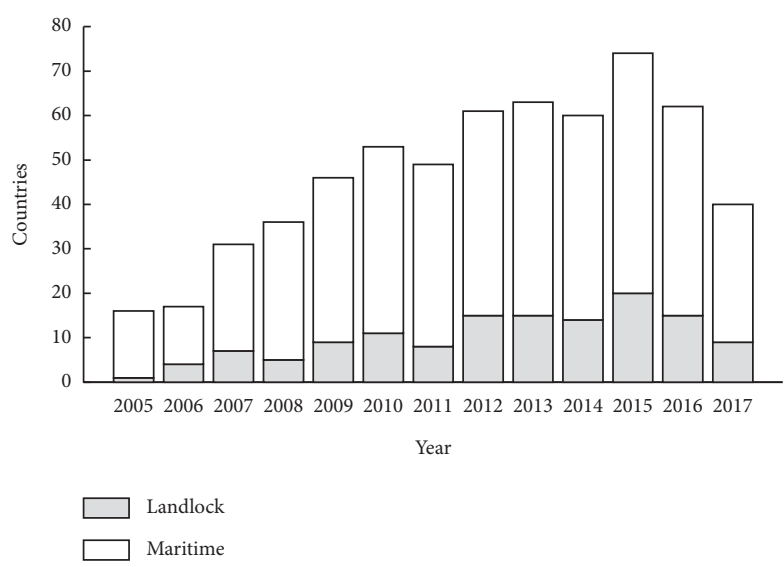

(c)

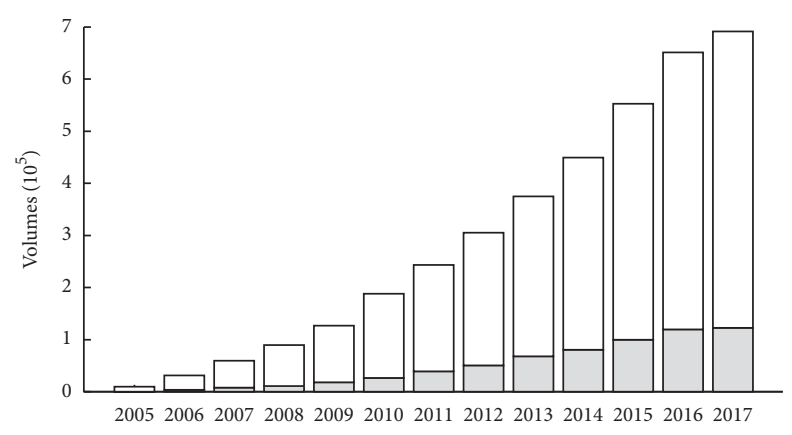

Year

(b)

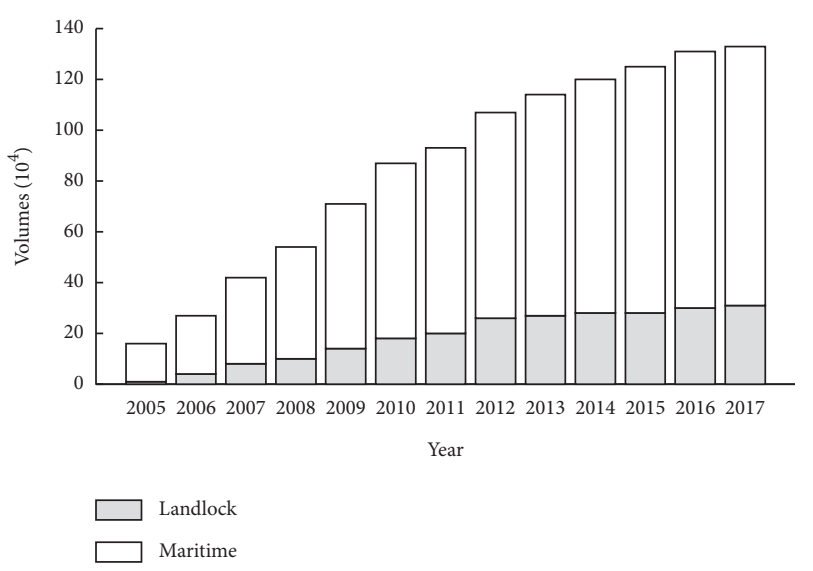

(d)

FIGURE 15: Accumulated maritime and landlocked IEs (2005-2017) (No. 5): (a) annual millions; (b) annual accumulated millions; (c) annual involved countries; (d) annual accumulated involved countries.

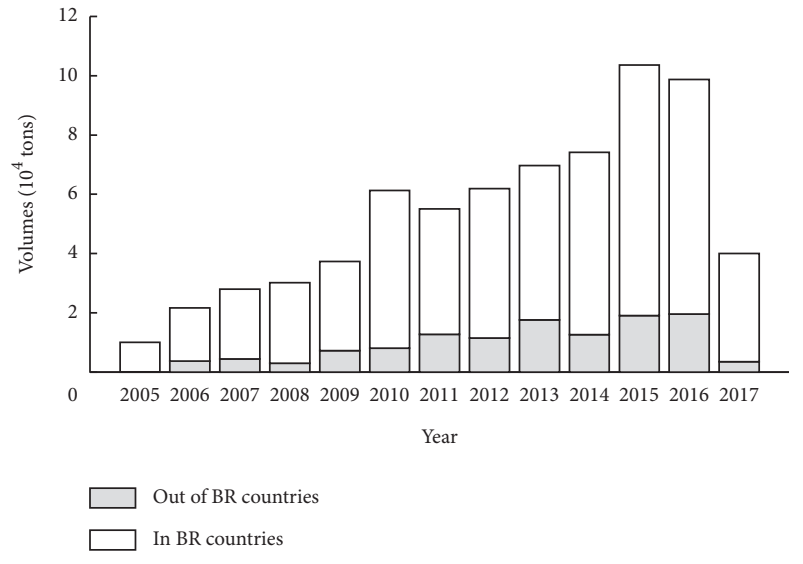

(a)

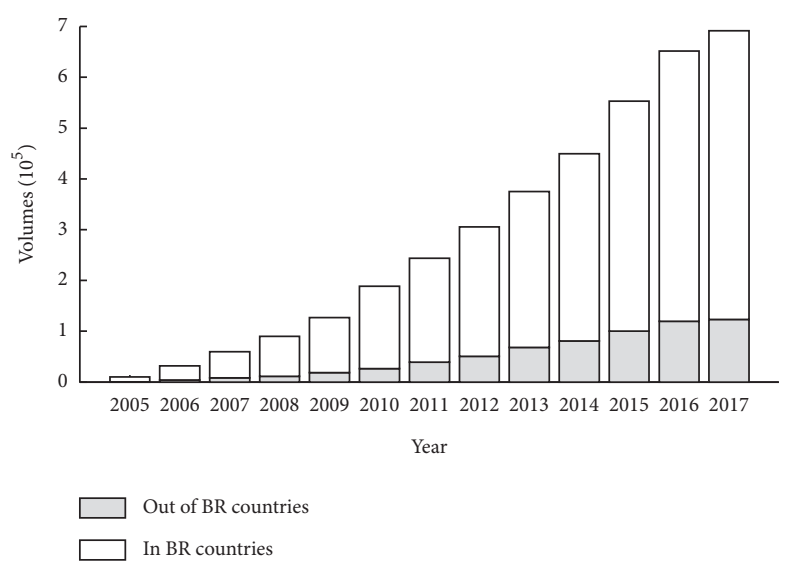

(b)

Figure 16: Continued. 


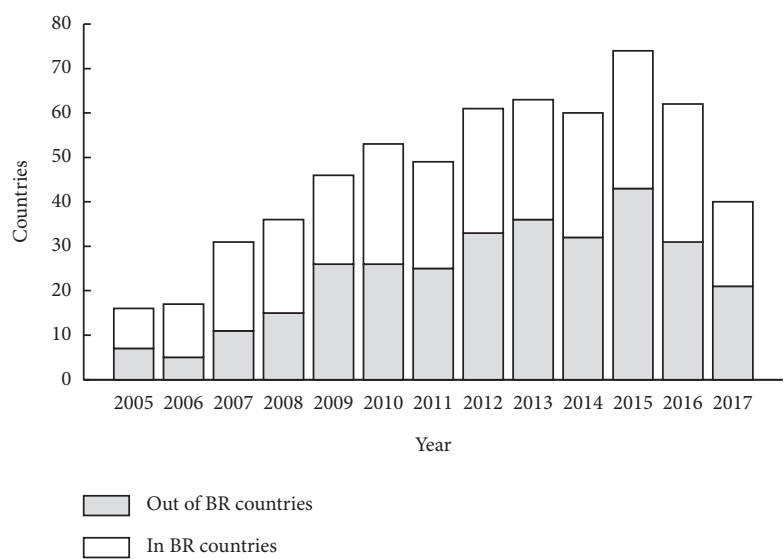

(c)

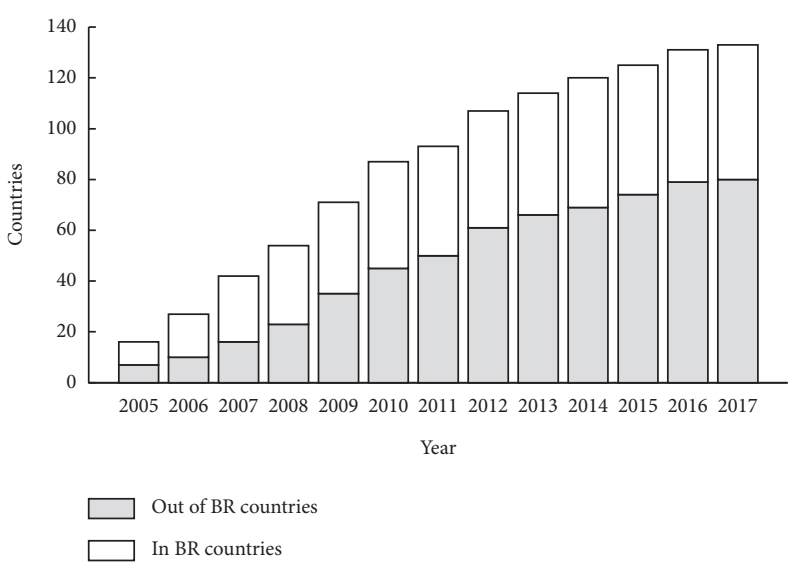

(d)

FIGURE 16: China's overseas construction projects in or out of BR (No. 5): (a) annual millions; (b) accumulated millions; (c) annual countries; (d) accumulated countries.

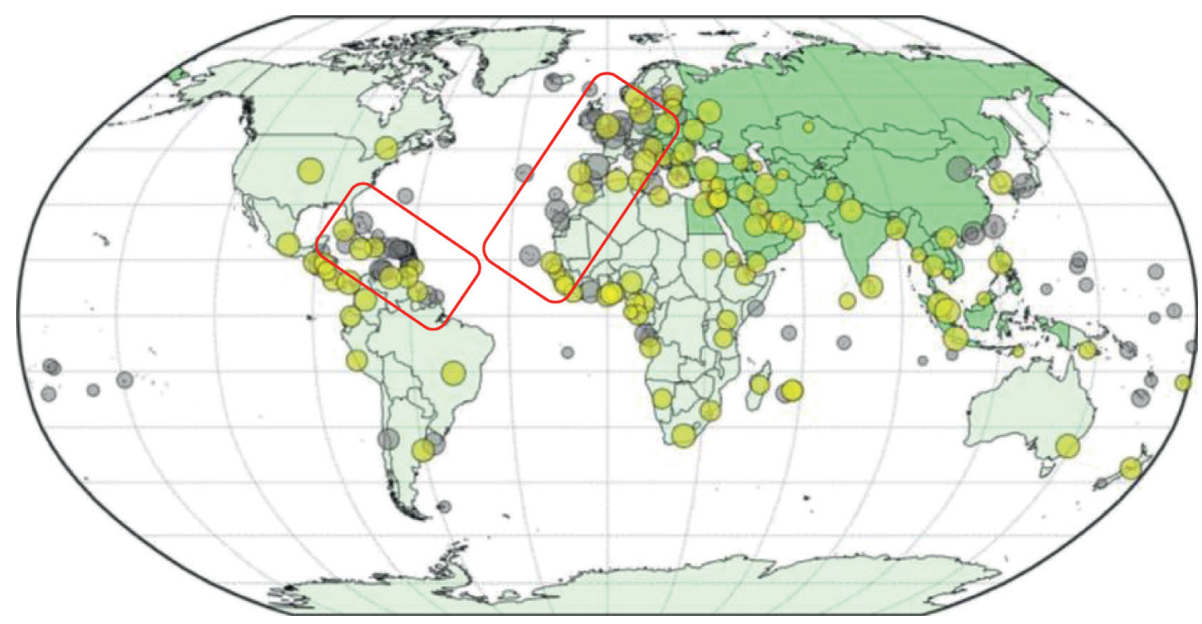

(a)

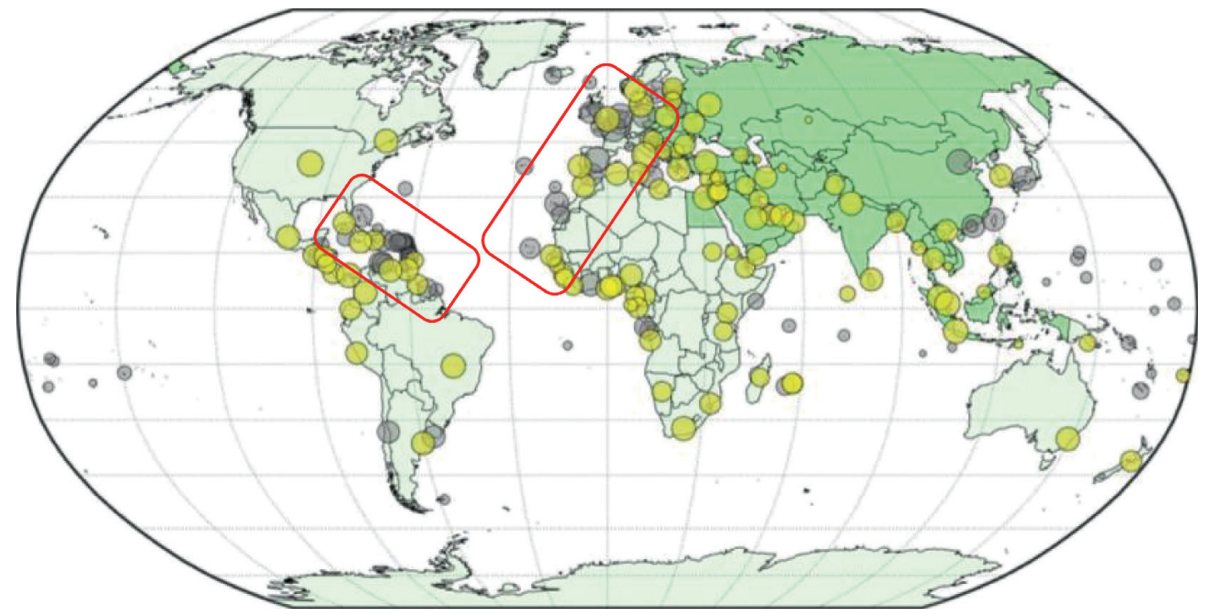

(b)

Figure 17: Continued. 


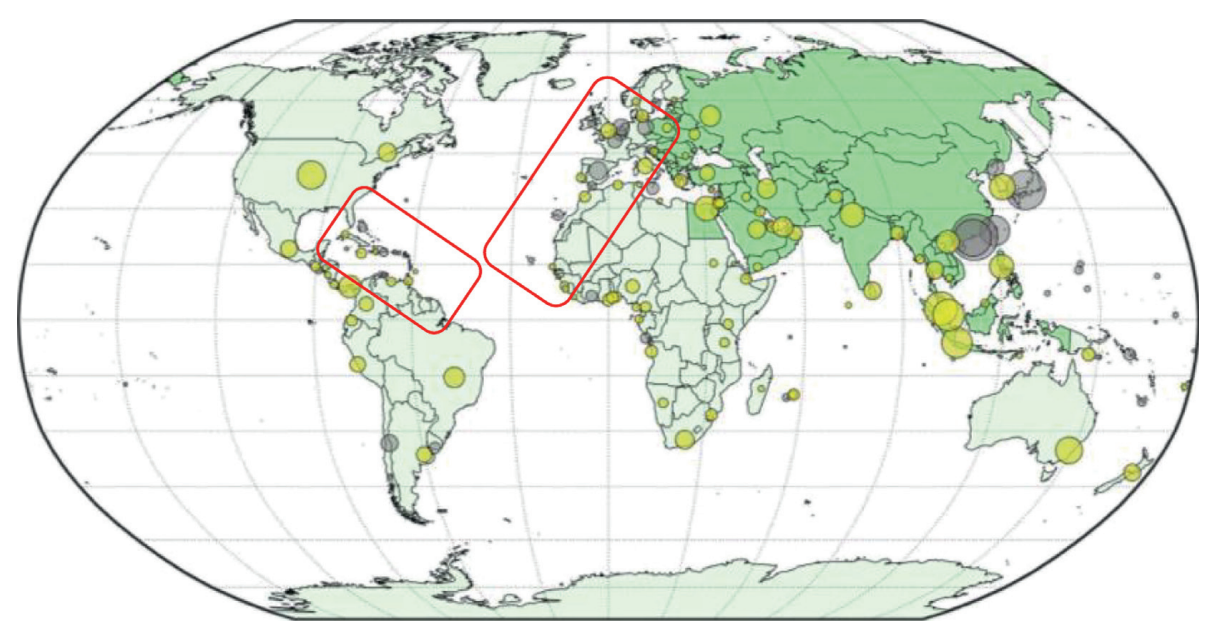

(c)

FIGURE 17: China's overseas construction projects coupled with the national shipping network (No. 6). (a) Coupled with the global maritime network of significances (PageRank centrality); (b) coupled with the global maritime network of flows (degree centrality); (c) coupled with China's maritime flows.

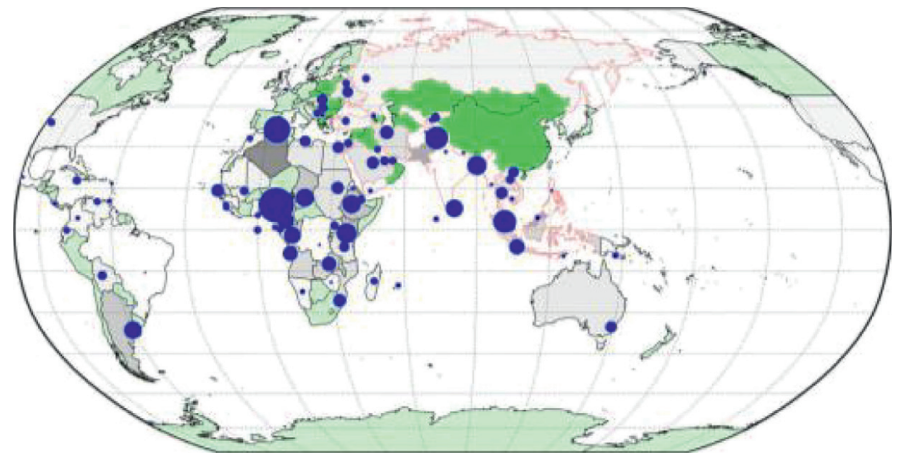

(a)

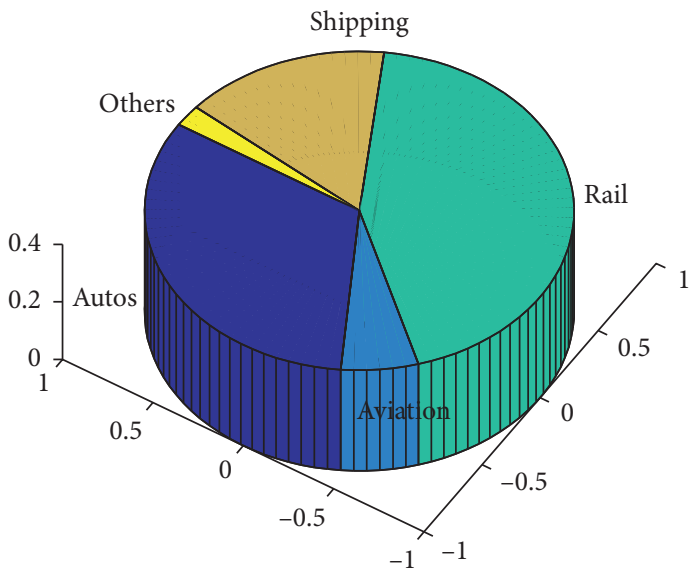

(b)

FIGURE 18: China's overseas transport construction projects (2005-2017) (No. 7): (a) spatial distribution; (b) sector distribution.

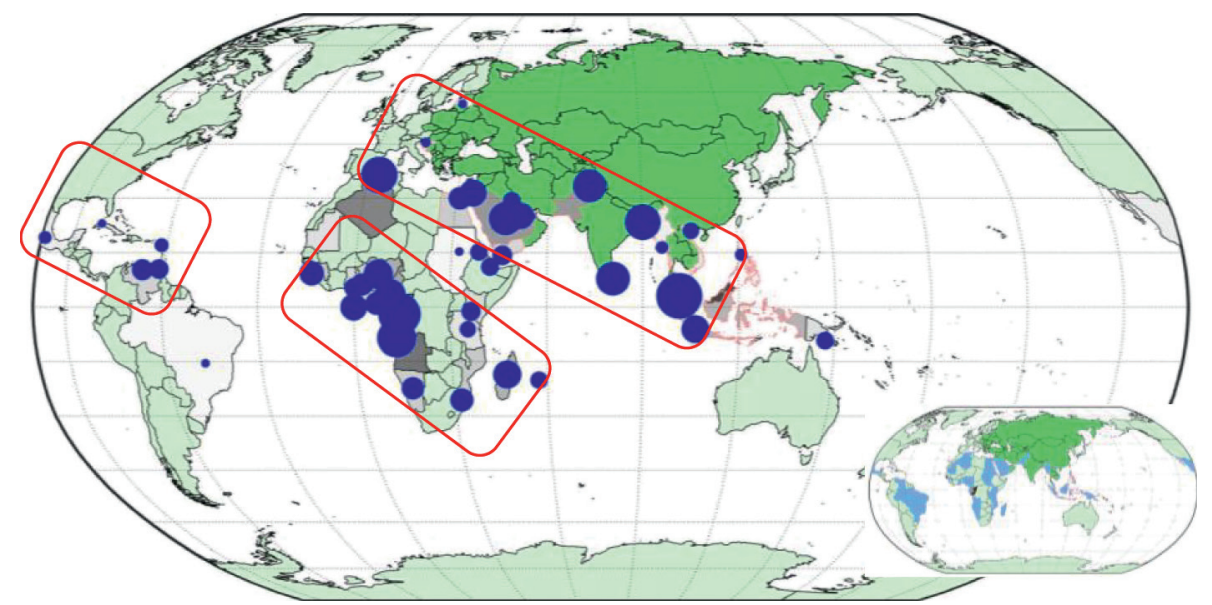

FIGURE 19: China's overseas shipping construction projects (2005-2017). 


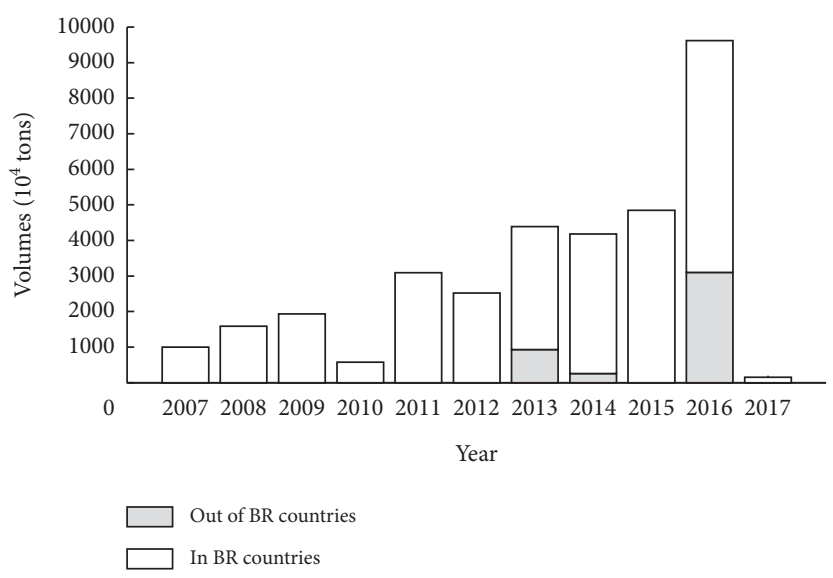

(a)

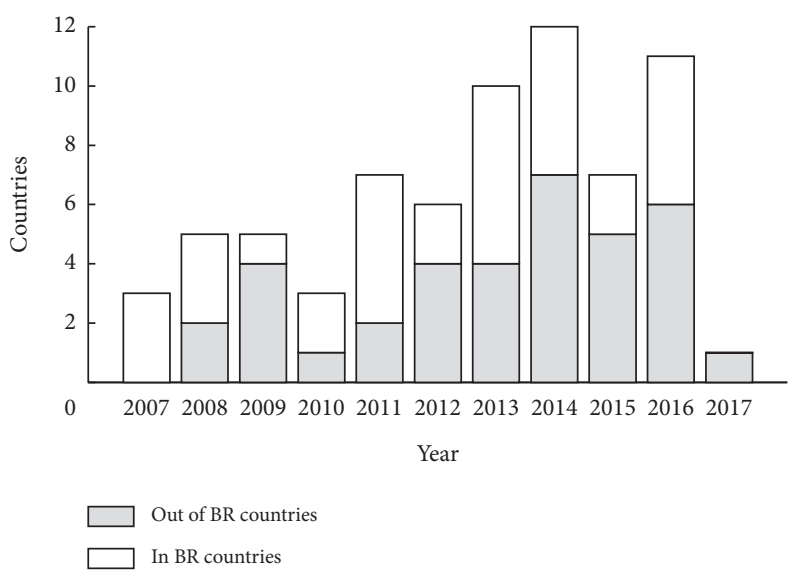

(c)

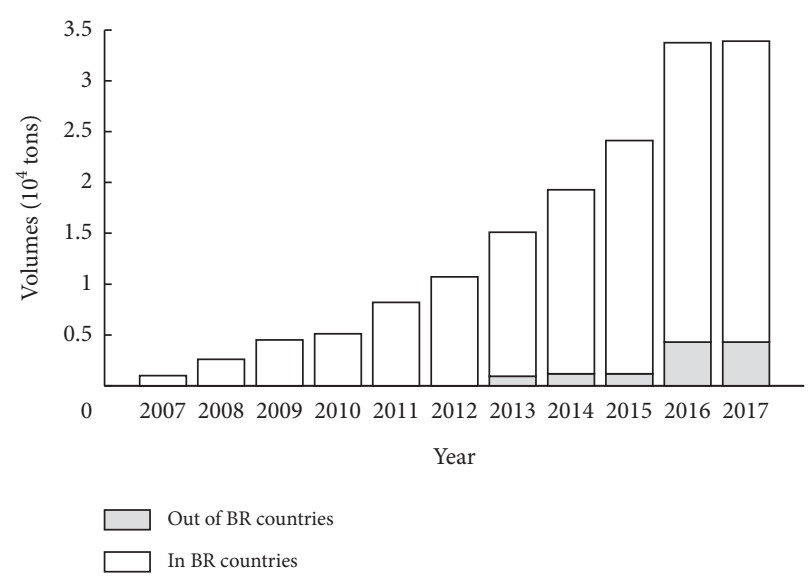

(b)

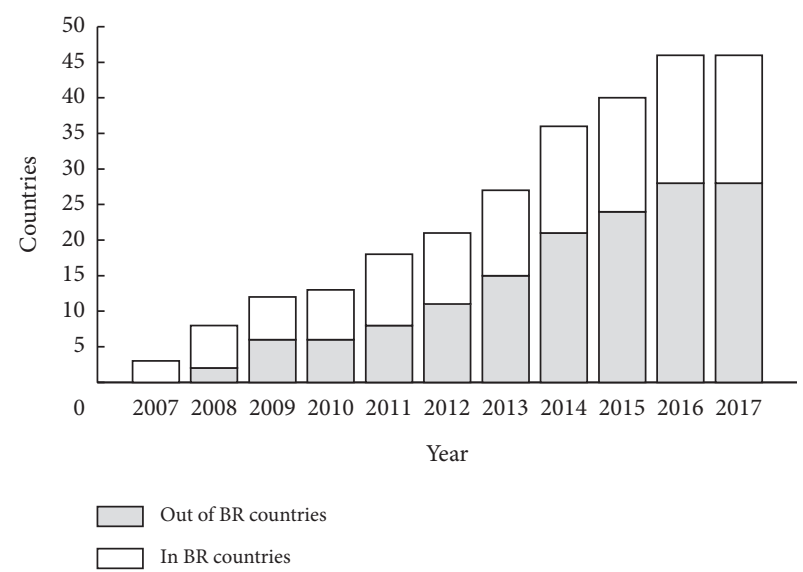

(d)

FIgURe 20: China's overseas shipping construction projects in or out of BR (2005-2017): (a) annual millions; (b) accumulated millions; (c) annual countries; (d) accumulated countries.

from the differences in culture, politics, business models, and even engineering contracting modes. It is beneficial for China's oversea engineering companies to adopt localization strategies.

(4) The maritime network can be a potential predictor for COCP. The present COCP may primarily depend on the maritime channel for transport. So, the potential market can be portrayed based on the maritime network and its tendencies. Here, the global maritime network and the maritime network anticipated by China may share the same holistic trends. In this aspect, the development of China and the global maritime network are much consistent. Also, besides the maritime network's prediction or indications, with the development of BRI, the landside transport and communication capability will be enhanced and so the landlocked IEs will be the most potential targets of COCP. Generally, the maritime networks are used for operations optimization and management. However, the global maritime network may be a mirror of global trade, economy, and supply chains and possibly be used to investigate them by data-driven methods. Coupling the maritime network, COCP, and BRI by networks, this study provides a new tool to study the impacts of BRI on specific industries, the investment opportunities of COCP, and the maritime industry. China can also use this tool to tell the motivation and stories of the BRI and "go out" strategies.

(5) Transport infrastructures are generally premising for developing other sectors. A dream of the BRI is to push forward the construction of international passageways and form an infrastructure network connecting all subregions in Asia and between Asia, Europe, and Africa step by step [1]. However, we must view the global shipping system in line with trade and a part of globalization. Road, rail, aviation, tunnel, and shipping are different means and roles for connecting the world. At present, the BR countries will mostly focus on the road and rail transport systems when the BRI is continuously on the way of development. The maritime network will generate more potential opportunities for China to connect the world. As a Chinese saying, "to be rich, 
build roads first." In the BRI, the SREB portrays a picture of road and railway transportation network in Eurasia, while the MSR depicts many opportunities to connect Eurasia and even the world through maritime transportation. As revealed by this study, maritime transportation contributes to the COCP and reversely, especially in the transport and shipping sectors, the COCP can enhance maritime transportation.

\section{Conclusion}

This study coupled the data sets on COCP, maritime network, and BRI and investigated them. The COCP is a representative of China's global business and "go out" national strategy; the BRI can produce a prosperous future when China continuously develops it; the maritime network is a global carrier of these businesses and dreams, especially bulk volumes of cargo flow involved. In methodology aspects, this study used data-driven analytics methods. Second, this study created an embodied maritime network from the three data sets. Thus, the network analysis models and algorithms were tested upon the network. Third, this study analyzed the time and spatial distribution and evolution simultaneously to reveal the hidden patterns in the maritime network. By utilizing geographical visualization methods, tendencies and patterns can be intuitively observed and explained. These methodological contributions can be extended to applications based on big data and coupled analysis.

The analytical experiments also contribute to discovering the global opportunities related to COCP and BRI. First, this study investigated the existing and potential regional markets by time and spatial analysis. Eurasia and Africa are existing regional markets, while South America, West Europe, and North Africa begin to release great opportunities. Second, transport is a booming sector of COCP, and the different subsectors (mostly road, rail, tunnel, and shipping) present different focuses and tendencies. The landlocked IEs are potential targets when the transport infrastructures are well developed. The maritime IEs, especially in West Europe and America, may create opportunities. Third, the BRI even can be shaped by the time and spatial analysis. As a discovery, the BR region and especially the MSR had emerged with a definite shape ten years ago. In this sense, the BRI can be examined solely by geopolitics and neglecting its emergency from the world economy and China's historical international business. This discovery is a new explanation for the foundation of BRI. The BRI gives additional opportunities in developing the SREB and the connectivity between BR and the world.

This study used network analysis and visualization methods to reveal the relations among the COCP, maritime network, and BRI. The time-spatial inference models among networks can be formulated in the future study. By analytical experiments on the time series data and networks, this study examined some time and spatial patterns and tendencies. The policy implications will be studied in the views of China, regions, and global communities in the future.

\section{Data Availability}

The data used to support the findings of this study are available from the corresponding author upon reasonable request.

\section{Conflicts of Interest}

The authors declare that they have no conflicts of interest.

\section{Acknowledgments}

The National Natural Science Foundation of China (71871136) partially supported this study.

\section{References}

[1] NDRC, Vision and Actions on Jointly Building Silk Road Economic Belt and 21st-Century Maritime Silk Road, National Development and Reform Commission, Chengdu, China, 2015, http://en.ndrc.gov.cn/newsrelease/201503/t20150330_ 669367.html.

[2] J.-M. F. Blanchard and C. Flint, "The geopolitics of China's Maritime Silk Road initiative," Geopolitics, vol. 22, no. 2, pp. 223-245, 2017.

[3] A. Ansar, B. Flyvbjerg, A. Budzier, and D. Lunn, "Does infrastructure investment lead to economic growth or economic fragility? Evidence from China," Oxford Review of Economic Policy, vol. 32, no. 3, pp. 360-390, 2016.

[4] Z.-H. Hu, "Vietnam's connectivity and embeddedness in the Maritime Silk Road and Global Maritime Network," Institute of Electrical EE Access, vol. 7, pp. 79592-79601, 2019.

[5] AEI, China Global Investment Tracker, American Enterprise Institute, Washington, DC, USA, (http://www.aei.org/chinaglobal-investment-tracker/), 2017.

[6] Z. Y. Zhao and L. Y. Shen, "Are Chinese contractors competitive in international markets?" Construction Management and Economics, vol. 26, no. 3, pp. 225-236, 2008.

[7] S. Godfrey and A. Ross, "China and Africa: the new water world," Waterlines, vol. 35, no. 1, pp. 12-17, 2016.

[8] L. S. Pheng and J. Hongbin, "Internationalization of Chinese construction enterprises," Journal of Construction Engineering and Management, vol. 129, pp. 589-598, 2003.

[9] S. L. Sun, Y. Zhang, and Z. Chen, "The challenges of Chinese outward investment in developed countries: the case of CITIC Pacific's Sino Iron Project in Australia," Thunderbird International Business Review, vol. 55, no. 3, pp. 313-322, 2013.

[10] C. Chen and R. J. Orr, "Chinese contractors in Africa: home government support, coordination mechanisms, and market entry strategies," Journal of Construction Engineering and Management, vol. 135, no. 11, pp. 1201-1210, 2009.

[11] A. W. Gadzala, "From formal- to informal-sector employment: examining the Chinese presence in Zambia," Review of African Political Economy, vol. 37, no. 123, pp. 41-59, 2010.

[12] M. Tan-Mullins and G. Mohan, "The potential of corporate environmental responsibility of Chinese state-owned enterprises in Africa," Environment, Development and Sustainability, vol. 15, no. 2, pp. 265-284, 2013.

[13] P. W. K. Yankson, A. B. Asiedu, K. Owusu, F. Urban, and G. Siciliano, "The livelihood challenges of resettled communities of the Bui dam project in Ghana and the role of Chinese dam-builders," Development Policy Review, vol. 36, pp. 476494, 2018. 
[14] L. Kiik, "Nationalism and anti-ethno-politics: why "Chinese Development" failed at Myanmar's Myitsone Dam," Eurasian Geography and Economics, vol. 57, no. 3, pp. 374-402, 2016.

[15] J. Y. Liu and S. P. Low, "Developing an organizational learning-based model for risk management in Chinese construction firms: a research agenda," Disaster Prevention and Management: An International Journal, vol. 18, pp. 170-186, 2009.

[16] Z. Shi, Z. Huang, X. Zhu, and J. Liu, "Modelling integrated risks of overseas power construction project: a case study in Uzbekistan," Journal of Engineering Science and Technology Review, vol. 9, no. 4, pp. 90-97, 2016.

[17] Y. Ke, F. Y. Y. Ling, and Y. Ning, "Public construction project delivery process in Singapore, Beijing, Hong Kong and Sydney," Journal of Financial Management of Property and Construction, vol. 18, no. 1, pp. 6-25, 2013.

[18] D. Hayes, "China builds a national gas pipeline grid," Pipeline World, vol. 1, no. 8, pp. 28-31, 2005.

[19] X. O. Zhu, "Demystifying the role of Chinese commercial actors in the shaping China's foreign assistance: the case of post-war Sri Lanka," Stability: International Journal of Security \& Development, vol. 4, no. 1, p. 24, 2015.

[20] J. Garlick, "Deconstructing the China-Pakistan economic corridor: pipe dreams versus geopolitical realities," Journal of Contemporary China, vol. 27, no. 112, pp. 519-533, 2018.

[21] S. Hidalgo-Gallego, R. Núñez-Sánchez, and P. Coto-Millán, "Game theory and port economics: a survey of recent research," Journal of Economic Surveys, vol. 31, pp. 854-877, 2017.

[22] N. Asgari, R. Z. Farahani, and M. Goh, "Network design approach for hub ports-shipping companies competition and cooperation," Transportation Research Part A: Policy and Practice, vol. 48, pp. 1-18, 2013.

[23] X. M. Fu, H. X. Chen, and Z. K. Xue, "Construction of the Belt and Road trade cooperation network from the multi-distances perspective," Sustainability (Switzerland), vol. 10, 2018.

[24] R. Konings, E. Kreutzberger, and V. Maraš, "Major considerations in developing a hub-and-spoke network to improve the cost performance of container barge transport in the hinterland: the case of the port of rotterdam," Journal of Transport Geography, vol. 29, pp. 63-73, 2013.

[25] Z. H. Hu, C. J. Liu, and P. Tae-Woo Lee, "Analyzing interactions between Japanese ports and the Maritime Silk Road based on complex networks," Complexity, vol. 202018 pages, 2020.

[26] B. D. Brouer, G. Desaulniers, and D. Pisinger, "A matheuristic for the liner shipping network design problem," Transportation Research Part E: Logistics and Transportation Review, vol. 72, pp. 42-59, 2014.

[27] S. Wang, Z. Liu, and Q. Meng, "Segment-based alteration for container liner shipping network design," Transportation Research Part B: Methodological, vol. 72, pp. 128-145, 2015.

[28] C. Ducruet and F. Zaidi, "Maritime constellations: a complex network approach to shipping and ports," Maritime Policy \& Management, vol. 39, no. 2, pp. 151-168, 2012.

[29] Z. H. Hu, C. J. Liu, W. Chen, Y. G. Wang, and C. Wei, "Maritime convection and fluctuation between Vietnam and China: a data-driven study," Research in Transportation Business and Management, vol. 34, 2020.

[30] Y. Wang and K. Cullinane, "Determinants of port centrality in maritime container transportation," Transportation Research Part E: Logistics and Transportation Review, vol. 95, pp. 326-340, 2016.
[31] J. M. W. Low, S. W. Lam, and L. C. Tang, "Assessment of hub status among Asian ports from a network perspective," Transportation Research Part A: Policy and Practice, vol. 43, no. 6, pp. 593-606, 2009.

[32] Z. Chong, C. Qin, and S. Pan, "The evolution of the Belt and Road Trade network and its determinant factors," Emerging Markets Finance and Trade, vol. 55, no. 14, pp. 3166-3177, 2019.

[33] J. Jiang, L. H. Lee, E. P. Chew, and C. C. Gan, "Port connectivity study: an analysis framework from a global container liner shipping network perspective," Transportation Research Part E: Logistics and Transportation Review, vol. 73, pp. 47-64, 2015.

[34] J. S. L. Lam and W. Y. Yap, "Dynamics of liner shipping network and port connectivity in supply chain systems: analysis on East Asia," Journal of Transport Geography, vol. 19, no. 6, pp. 1272-1281, 2011.

[35] T. Y. Pham, J. W. Jeon, V. L. Dang, Y. D. Cha, and G. T. Yeo, "A longitudinal analysis of concentration developments for container terminals in northern Vietnam," The Asian Journal of Shipping and Logistics, vol. 32, no. 3, pp. 157-164, 2016.

[36] S. Wang and Q. Meng, "Sailing speed optimization for container ships in a liner shipping network," Transportation Research Part E: Logistics and Transportation Review, vol. 48, no. 3, pp. 701-714, 2012.

[37] A. Scott, "The value of information sharing for truckload shippers," Transportation Research Part E: Logistics and Transportation Review, vol. 81, pp. 203-214, 2015.

[38] Y. Kou, L. Liu, and M. Luo, "Lead-lag relationship between new-building and second-hand ship prices," Maritime Policy \& Management, vol. 41, no. 4, pp. 303-327, 2014.

[39] L. Wu, Y. Xu, Q. Wang, F. Wang, and Z. Xu, "Mapping global shipping density from AIS data," Journal of Navigation, vol. 70, no. 1 , pp. $67-81,2017$.

[40] F. Xiao, H. Ligteringen, C. Van Gulijk, and B. Ale, "Comparison study on AIS data of ship traffic behavior," Ocean Engineering, vol. 95, pp. 84-93, 2015.

[41] A. Mazaheri, J. Montewka, P. Kotilainen, O.-V. Edvard Sormunen, and P. Kujala, "Assessing grounding frequency using ship traffic and waterway complexity," Journal of Navigation, vol. 68, no. 1, pp. 89-106, 2015.

[42] R. Adland, G. Fonnes, H. Jia, O. D. Lampe, and S. P. Strandenes, "The impact of regional environmental regulations on empirical vessel speeds," Transportation Research Part D: Transport and Environment, vol. 53, pp. 37-49, 2017.

[43] G. Wilmsmeier, J. Monios, and G. Pérez-Salas, "Port system evolution-the case of Latin America and the Caribbean," Journal of Transport Geography, vol. 39, pp. 208-221, 2014.

[44] T. Alderton and N. Winchester, "Flag states and safety: 1997-1999," Maritime Policy \& Management, vol. 29, no. 2, pp. 151-162, 2002.

[45] A. H. Alizadeh, "Trading volume and volatility in the shipping forward freight market," Transportation Research Part E: Logistics and Transportation Review, vol. 49, no. 1, pp. 250265, 2013.

[46] H. Kohli, "Looking at China's Belt and Road Initiative from the Central Asian perspective," Global Journal of Emerging Market Economies, vol. 9, no. 1-3, pp. 3-11, 2017.

[47] P. T.-W. Lee, Z.-H. Hu, S.-J. Lee, K.-S. Choi, and S.-H. Shin, "Research trends and agenda on the belt and road (B \& R) initiative with a focus on maritime transport," Maritime Policy \& Management, vol. 45, no. 3, pp. 282-300, 2018. 
[48] M. L. Gorbunova and I. D. Komarov, "Emerging integration projects in Eurasia: a search for new cooperation formats?" Journal of Chinese Economic and Business Studies, vol. 15, no. 3, pp. 229-247, 2017.

[49] S. Ma and M. Liu, "Spatial correlation effect of China's outward foreign direct investment in countries along the one belt and one road," Pacific Economic Review, vol. 25, no. 2, pp. 228-249, 2020.

[50] N. Mou, Y. Fang, T. Yang, and L. Zhang, "Assortative analysis of bulk trade complex network on Maritime Silk Road," IEEE Access, vol. 8, pp. 131928-131938, 2020.

[51] X. Xi, J. Zhou, X. Gao, D. Liu, H. Zheng, and Q. Sun, "Impact of changes in crude oil trade network patterns on national economy," Energy Economics, vol. 84, 2019.

[52] Q. Zhang and Q. Zeng, "Analyzing the shipping network of the maritime silk road (MSR) based on a complex network," Journal of Coastal Research, vol. 98, no. sp1, pp. 344-349, 2019.

[53] Z.-H. Hu, "Shipping Earth: a framework for big data driven maritime port and shipping network," in International Conference on Foundation Commemorative of the China Center of JRI in Association with Seminar for Memory of the Late Professor Emeritus Richard O. GossInha University, Incheon, South Korea, 2017.

[54] K. Niazi, M. Shoaib, and S. Qiulian, "Micro impacts of a macro-level trading partnership: effects of China's Belt and Road Initiative in Pakistan," American Journal of Economics and Sociology, vol. 79, no. 1, pp. 301-322, 2020.

[55] M. T. Yalew and G. Changgang, "China's "Belt and Road Initiative": implication for land locked Ethiopia," Insight on Africa, vol. 12, no. 2, pp. 175-193, 2020. 